Received 00th January 20xx, Accepted 00th January 20xx DOI: $10.1039 / \times 0 \times x 00000 x$

\title{
Integrating PtNi Nanoparticles on NiFe Layered Double Hydroxide Nanosheets as Bifunctional Catalyst for Hybrid Sodium-Air Batteries
}

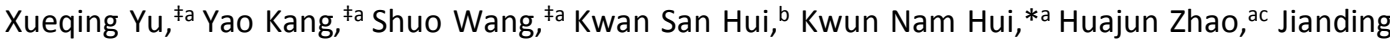 \\ $\mathrm{Li}{ }^{\text {a }}$ Bo Li, ${ }^{a}$ Jincheng $\mathrm{Xu},{ }^{a}$ Liang Chen, ${ }^{* d e}$ and Huaiyu Shao*a
}

\begin{abstract}
Hybrid sodium-air batteries (HSABs) are emerging systems for next-generation energy storage owing to high theoretical energy density, high specific capacity, low cost, and environmental friendliness. However, ungratified energy efficiency, large overpotential, and poor cycling stability associated with sluggish oxygen reduction reaction/oxygen evolution reaction (ORR/OER) at air electrodes hamper their further development. Herein, we report a facile electrodeposition method to construct three-dimensional nickel defect-rich nickel iron layered double hydroxide nanosheets decorated with platinum nickel alloyed nanoparticles grown on macroporous nickel foam substrates ( $\mathrm{PtNi} / \mathrm{Ni}_{x} \mathrm{Fe}$ LDHs) as a binder-free electrocatalyst. The as-prepared catalyst demonstrates low overpotential ( $265 \mathrm{mV}$ at the current density of $\left.10 \mathrm{~mA} \mathrm{~cm}{ }^{-2}\right)$, small Tafel slope $\left(22.2 \mathrm{mV} \mathrm{dec}^{-1}\right)$ toward OER and high half-wave potential $(0.84 \mathrm{~V})$ of ORR, as well as superior long-term stability compared to commercial catalysts. Theoretical calculations reveal that $\mathrm{Ni}$-top site of $\mathrm{PtNi} / \mathrm{Ni}_{x} \mathrm{Fe}$ LDHs works as active sites for enhanced OER/ORR activities. The fabricated HSAB with PtNi/Ni ${ }_{x} F e ~ L D H s$ as air cathode displays not only an initial low overpotential gap $(0.50 \mathrm{~V})$ but also superior rechargeability and structure stability with high round-trip efficiency ( $79.9 \%)$ over 300 cycles. These results provide a novel design of bifunctional and binder-free catalysts as cathode for metalair batteries.
\end{abstract}

\section{Introduction}

Hybrid sodium-air batteries (HSABs), as one of the most auspicious rechargeable technologies, have attracted much attention for future electrical energy storage (EES) systems because of their high theoretical specific capacity, high energy density, great resource abundance, as well as environmental friendliness. ${ }^{1}$ However, the unsatisfied performance such as low energy efficiency, high overpotential, and poor cycling stability, due to the sluggish reaction rate of oxygen reduction reaction/oxygen evolution reaction (ORR/OER) of the air electrodes, needs further improvement in practical applications. ${ }^{2,} 3$ Meanwhile, the inert and insulated polymer binders such as Nafion or polytetrafluoroethylene (PVDF) utilized in the manufacturing of air electrodes, severely inhibit electron/ion transfer and deteriorate the electrical

a. Joint Key Laboratory of the Ministry of Education, Institute of Applied Physics and Materials Engineering, University of Macau, Avenida da Universidade, Taipa, Macau SAR, China.Email: bizhui@um.edu.mo, hshao@um.edu.mo

b. Engineering, Faculty of Science, University of East Anglia, Norwich, NR4 7TJ, United Kingdom

Department of Materials Science and Engineering, Southern University of Science and Technology, Shenzhen, Guangdong 518055, China

d. Ningbo Institute of Materials Technology and Engineering, Chinese Academy of Sciences, Ningbo, Zhejiang 315201, China.Email: chenliang@nimte.ac.cn

e. University of Chinese Academy of Sciences, Beijing, 100049, China

${ }^{\ddagger}$ These authors contributed equally.

Electronic Supplementary Information (ESI) available: [details of any supplementary information available should be included here]. See DOI: 10.1039/x0xx0000x conductivity, further aggravate the above problems. ${ }^{4}$ Therefore, the development of binder-free ORR/OER electrocatalysts with high efficiency and durable electrocatalytic performances is an urgent task.

Layered double hydroxides (LDHs), i.e., hydrotalcite-like materials, are composed of positively charged layers including divalent (e.g., $\mathrm{Ni}^{2+}, \mathrm{Mn}^{2+}, \mathrm{Co}^{2+}$ ) and trivalent metal cations (e.g., $\mathrm{Fe}^{3+}, \mathrm{Al}^{3+}, \mathrm{Cr}^{3+}$ ) coordinated to hydroxide anions, with exchangeable interlayer anions (e.g., $\left.\mathrm{CO}_{3}{ }^{2-}, \mathrm{NO}_{3}{ }^{-}, \mathrm{Cl}^{-}\right) .^{5-7}$ Many studies demonstrated that $\mathrm{LDHs}$ show great electrocatalytic performance toward OER, because of their unique layered structure which provides more surface sites, wide tunability of metal species/ratio and large interlayer spacing. ${ }^{8}$ Among various promising alternatives, the first-row transition metals (e.g., $\mathrm{Ni}, \mathrm{Fe}, \mathrm{Co}$, and $\mathrm{Mn}$ ) LDHs have attracted tremendous interest owing to their large earth abundance and remarkable OER performance. ${ }^{8}, 9$ Dai's group first reported NiFe LDHs exhibit higher electrocatalytic activity and stability for OER than commercial precious metal catalysts in alkaline solutions $(\mathrm{pH}=13-14) .{ }^{9}$ Subsequently, much effort has been devoted to synthesize NiFe LDHs with different morphologies including nanosheets, ${ }^{10}$ nanoplatelets, ${ }^{11}$ nanowires, ${ }^{12}$ and hollow nanoprisms ${ }^{13}$ to achieve high electroactive sites and decrease ion diffusion length. However, NiFe LDHs suffer from low intrinsic conductivity, leading to sluggish OER properties. One of the effective ways to alleviate this problem is immobilizing or directly growing LDHs on electrically conductive materials. In particular, nickel foam (NF) is well-recognized as conductive 
substrates-supported for catalyst owing to its abundant accessible surface areas in three-dimensional (3D) framework. Meanwhile, the macroscopic porous structure of $\mathrm{Ni}$ foam also facilitates the rapid mass transfer and gaseous bubbles dissipate. Thus it may dramatically reduce the so-called "bubble overpotentials", which is one of the major causes of energy loss, especially under high current densities. ${ }^{14}$ Additionally, the introduction of cation vacancies has been reported to increase the electroactive sites to enhance the electrocatalytic properties of LDHs. ${ }^{6,10,15}$ For example, Wang and co-workers reported NiFe LDHs nanosheets as a prominent OER electrocatalyst with rich iron or nickel vacancies, which can effectively tune the surface electronic structure and improve the adsorption capacity of OER intermediates $\left({ }^{*} \mathrm{O}\right) .{ }^{10}$ Moreover, abundant $\mathrm{Ni}^{2+}$ defects on $\mathrm{Ni}(\mathrm{OH})_{x}$ have been demonstrated as essential anchoring sites in stabilizing single-atomic-site $\mathrm{Pt}$ catalyst. ${ }^{15}$ X-ray absorption near-edge structure (XANES) spectra analysis together with density functional theory (DFT) calculations revealed that the $\mathrm{Ni}^{2+}$ vacancies eliminate the spatial segregation between $\mathrm{Pt}$ atoms and uncoordinated $\mathrm{O}$ ones and decrease the formation energy of $\mathrm{Pt}$ atoms by promoting charge transfer from $\mathrm{Ni}(\mathrm{OH})_{x}$ to $\mathrm{Pt}$, leading to efficient anchoring of $\mathrm{Pt}$ atoms on defect-rich $\mathrm{Ni}(\mathrm{OH})_{x}$. Likewise, numerous reported non-Pt-based catalysts still have higher overpotentials and poor catalytic performance compared to platinum. It is still challenging to develop a method for improving Pt utilization efficiency and enhancing its electrocatalytic performance.

Here, a facile electrochemical approach is proposed to synthesize well-dispersed platinum nickel alloyed nanocrystals on the surface of defect-rich nickel iron layered double hydroxide ( $\left.\mathrm{PtNi} / \mathrm{Ni}_{x} \mathrm{Fe} \mathrm{LDHs}\right)$. The introduction of $\mathrm{Ni}^{2+}$ vacancies in NiFe LDHs nanosheets alters the surface electronic structure and properties, which not only promotes the adsorption of OER intermediates but also essential for stabilizes the small PtNi alloy nanocrystals. Bring an alloying element to Pt-based catalyst could directly reduce Pt usage, modulate the electronic structure of Pt through strain and ligand effects. The threedimensional (3D) interconnected hierarchically porous structure and uniformly decorated ultrafine alloy nanoclusters of $\mathrm{PtNi} / \mathrm{Ni}_{\mathrm{x}} \mathrm{Fe}$ LDHs enhance the accessibility of active sites and the overall electronic conductivity, lower overall ORR/OER barriers, thus demonstrating excellent bifunctional catalytic activity and long term durability in alkaline solution. Based on the satisfactory electrocatalytic properties, the assembled HSAB with $\mathrm{PtNi} / \mathrm{Ni}_{x} \mathrm{Fe}$ LDHs as air electrode delivers initial high discharge voltage, low overpotential gap, high round trip efficiency, as well as superior rechargeability and long term durability over 300 cycles, thus highlighting its enormous potential in next-generation energy storage and conversion system applications.

\section{Results and discussion}

As described in Fig. 1, a simple three-step synthesis method was applied to fabricate $\mathrm{PtNi} / \mathrm{Ni}_{\mathrm{x}} \mathrm{Fe} \mathrm{LDHs}$ nanocomposites onto the surface of NF substrates (see details in the Experimental
Section). Briefly, NiZnFe LDHs nanosheets were electrodeposited on the $\mathrm{Ni}$ foam in an electrolyte containing $\mathrm{Ni}$ and Fe nitrates at room temperature. Subsequently, the assynthesized NiZnFe LDHs were etched using strong alkaline solutions to create $\mathrm{Ni}^{2+}$ vacancies (denoted as $\mathrm{Ni}_{x} \mathrm{Fe}$ LDHs). Finally, uniform PtNi alloy nanocrystals were grown on $\mathrm{Ni}_{x} \mathrm{Fe}$ $\mathrm{LDHs} / \mathrm{Ni}$ foam substrates by continuous electrodeposition in $\mathrm{K}_{2} \mathrm{PtCl}_{6}$ and $\mathrm{NiSO}_{4}$ solution. By varying the molar ratio of platinum salt and nickel salt precursors, different $\mathrm{Pt} / \mathrm{Ni}$ alloy proportions could be tuned and formed on $\mathrm{Ni}_{x} \mathrm{Fe}$ LDHs. Samples prepared from various molar ratio $\mathrm{Pt}: \mathrm{Ni}=4: 0,3: 1,1: 1$ and $1: 3$ were denoted as $\mathrm{Pt} / \mathrm{Ni}_{x} \mathrm{Fe} \mathrm{LDHs}, \mathrm{Pt}_{3} \mathrm{Ni}_{1} / \mathrm{Ni}_{x} \mathrm{Fe}$ LDHs, $\mathrm{Pt}_{1} \mathrm{Ni}_{1} / \mathrm{Ni}_{x} \mathrm{Fe}$ $\mathrm{LDHs}$, and $\mathrm{Pt}_{1} \mathrm{Ni}_{3} / \mathrm{Ni}_{x} \mathrm{Fe} \mathrm{LDHs}$, respectively.

In refer to pristine $\mathrm{Ni}$ foam (Fig. S1a), scanning electron microscopy (SEM) images revealed the NiFe LDHs were uniformly coated on the $\mathrm{Ni}$ scaffolds surface with 3D hierarchical porous architecture (Fig. S1b). The highmagnification SEM images further exhibited that the NiFe LDHs were macroporous film assembled by nanosheets arrays ranging from 50 to $200 \mathrm{~nm}$ and an average thickness $9 \mathrm{~nm}$ (Fig. S1c, d), which is beneficial to improve the electrochemical active contact area and decrease the ions diffusion length in the electrolyte. As shown in different magnifications SEM images, the as-synthesized NiZnFe LDHs (Fig. S1e, f), Ni $x_{x} F e$ LDHs (Fig. 1b, c and S2a, b), Pt/Ni ${ }_{x} F e$ LDHs (Fig. $1 d$ and S2c, d), $\mathrm{Pt}_{3} \mathrm{Ni}_{1} / \mathrm{Ni}_{x} \mathrm{Fe}$ LDHs (Fig. 1e and S2e, f), $\mathrm{Pt}_{1} \mathrm{Ni}_{1} / \mathrm{Ni}_{x} \mathrm{Fe}$ LDHs (Fig. S3a) and $\mathrm{Pt}_{1} \mathrm{Ni}_{3} / \mathrm{Ni}_{x} \mathrm{Fe}$ LDHs (Fig. S3b) exhibited similar nanosheets morphology to NiFe LDHs (Fig. S1d). Interestingly, we noticed that the obtained $\mathrm{Ni}_{x} \mathrm{Fe}$ LDHs (Fig. 1c) by etching NiZnFe LDHs (Fig. S1f) nanosheets with a strong alkali solution kept the plate-
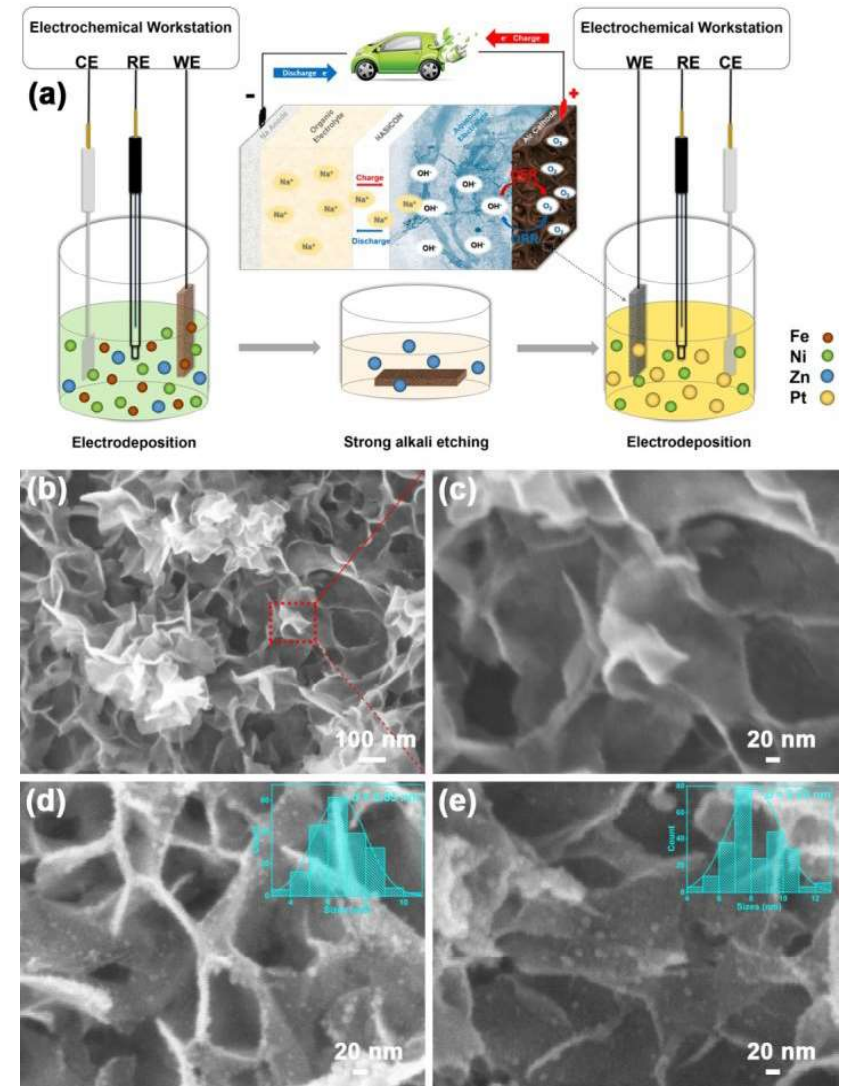

Fig. 1 (a) Schematic illustration of the electrosynthesis of $\mathrm{PtNi} / \mathrm{Ni}_{x} \mathrm{Fe}$ LDHs on $\mathrm{Ni}$ foam as air cathode in HSABs. SEM images of $(b, c) \mathrm{Ni}_{x} \mathrm{Fe}$ LDHs, (d) Pt/Ni $\mathrm{Ne}_{\mathrm{F}} \mathrm{LDHs}$, and (e) $\mathrm{Pt}_{3} \mathrm{Ni}_{1} / \mathrm{Ni}_{\mathrm{x}} \mathrm{Fe}$ LDHs. 
like morphology well, even clearer and thinner than NiZnFe LDHs. As depicted in Fig. $1 \mathrm{~d}$, the small $\mathrm{Pt}_{3} \mathrm{Ni}_{1}$ nanoclusters were uniformly anchored on the $\mathrm{Ni}_{x} \mathrm{Fe}$ LDHs surface in high yield, and the quantitative analysis by SEM-EDS (Fig. S4) manifested the atomic proportion of $\mathrm{Pt}$ was $0.41 \%$. The size of the $\mathrm{Pt}_{3} \mathrm{Ni}_{1}$ nanoclusters narrowly ranged from 4 to $13 \mathrm{~nm}$ with an average size of $8.2 \mathrm{~nm}$ (Fig. 1e, right insert). The high-resolution transmission electron microscopy (HRTEM) images further demonstrated that the $\mathrm{Pt}_{3} \mathrm{Ni}_{1}$ nanocrystals with small size $(<10$ $\mathrm{nm}$ ) uniformly decorated in $\mathrm{Ni}_{x} \mathrm{Fe}$ LDHs structural scaffold (Fig. $2 a, b$ ). Further magnified HRTEM image (Fig. 2c) indicated the high crystallinity of both NiFe LDH phases and PtNi phases together. The measured $d$-spacing of 0.22 and $0.195 \mathrm{~nm}$ matched well with the (111) and (200) plane of the facecentered cubic $(f c c)$ PtNi alloy structure, ${ }^{16}$ respectively, while the interplanar distance of $0.25 \mathrm{~nm}$ of the brighter background was indexed to the (012) plane of NiFe LDHs phase, ${ }^{17}$ which is agreed with the inset of selected-area electron diffraction (SAED) pattern in Fig. 2d. The high-angle annular dark-field (HAADF) scanning transmission electron microscopy (STM) image of $\mathrm{Pt}_{3} \mathrm{Ni}_{1} / \mathrm{Ni}_{x} \mathrm{Fe} \mathrm{LDHs}$ and the corresponding EDS mappings were shown in Fig. 2e-i that confirmed the existence and uniform distribution of $\mathrm{Ni}, \mathrm{Fe}, \mathrm{Pt}$, and $\mathrm{O}$ throughout the whole structure.

The XRD patterns (Fig. 3a) shown that the peaks observed at $33.7^{\circ}, 46.0^{\circ}$, and $60.0^{\circ}$ were assigned to the characteristic (012), (015) and (110) planes of LDH phase, ${ }^{17}$ which is agreed with the TEM data (Fig. 2d). Moreover, the as-synthesized Ni $\mathrm{N}_{\mathrm{x}} \mathrm{Fe}$ LDHs by strong alkali etching did not change the host crystal structure of NiFe LDHs (Fig. S7). Meanwhile, two diffraction peaks centred at $40.0^{\circ}$ and $46.9^{\circ}$ were also perceived, and the locations of the peaks between those of standard fcc Pt (No. JCPDS-04-0802) and standard $f c c \mathrm{Ni}$ (No. JCPDS-04-0850), which can be ascribed
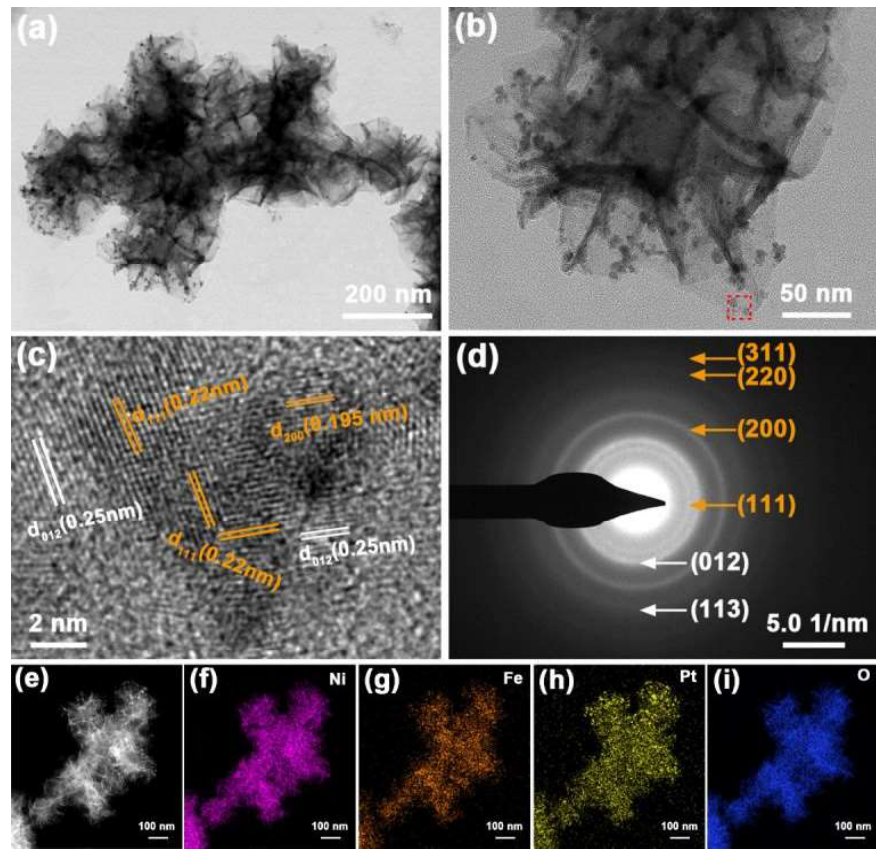

Fig. 2 (a, b) TEM images, (c) HRTEM image, (d) SAED pattern, and (e-i) the corresponding STEM-EDS elemental mappings of $\mathrm{Pt}_{3} \mathrm{Ni}_{1} / \mathrm{Ni}_{x} \mathrm{Fe}$ LDHs to (111) and (200) diffractions of the fcc PtNi alloy crystal structure ${ }^{16}$ respectively, further demonstrating the formation of the alloy structure.

The chemical valances of as-synthesized electrocatalysts (NiFe LDHs, NiZnFe LDHs, $\mathrm{Ni}_{x} \mathrm{Fe}$ LDHs, and $\mathrm{Pt}_{3} \mathrm{Ni}_{1} / \mathrm{Ni}_{x} \mathrm{Fe}$ LDHs) were further studied by X-ray photoelectron spectroscopy (XPS). The XPS survey of four nanocomposites (Fig. S8a) shown similar elemental compositions of $\mathrm{C}, \mathrm{O}, \mathrm{Ni}, \mathrm{Fe}$, and the detected of $\mathrm{Pt}$ peak signals reveals the successful introduction of Pt elements into $\mathrm{Ni}_{x} \mathrm{Fe}$ LDHs. In addition, $\mathrm{Zn}$ peaks almost disappeared after alkaline processing, confirming its selectively being etched from the NiZnFe LDHs during the base treatment. Fig. 3b displayed the high-resolution XPS spectrum of $\mathrm{Ni} 2 \mathrm{p}$ region in $\mathrm{Ni}_{x} \mathrm{Fe}$ LDHs and the pristine NiFe LDHs, which can be deconvoluted into $\mathrm{Ni}^{2+}-\mathrm{OH}, \mathrm{Ni}^{3+}-\mathrm{OH}$, and their corresponding satellite peaks, respectively. ${ }^{10}$ For the $\mathrm{NiFe} \mathrm{LDHs}$, the peak at approximate $852.8 \mathrm{eV}$ was assigned to Ni metal. Compared with NiFe LDHs, the percentage of $\mathrm{Ni}^{3+}$ distinctly increased from $18.4 \%$ to $35.4 \%$ after alkali etching, manifested the formation of $\mathrm{Ni}^{2+}$ vacancies on the surface of $\mathrm{Ni}_{x} \mathrm{Fe} \mathrm{LDHs}$ nanosheets. The introduction of $\mathrm{Ni}$ vacancies further altered the electronic structure of the $\mathrm{Ni}^{2+}$, resulting in the formation of $\mathrm{Ni}^{3+}$ sites with optimal unity occupancy of the $\mathrm{e}_{\mathrm{g}}$ orbital $\left(\mathrm{t}_{2 \mathrm{~g}}{ }^{6} \mathrm{e}_{\mathrm{g}}{ }^{1}\right)$, thus facilitating chargetransfer and enhancing the OER activity. ${ }^{10}$ Moreover, the abundance $\mathrm{Ni}$ vacancies also induced the strong interaction with adsorbing and stabilizing $\mathrm{Pt}$ atoms on the $\mathrm{Ni}_{x} \mathrm{Fe}$ LDHssupport in the subsequent PtNi deposition. The XPS spectrum of $\mathrm{Pt}$ (Fig. 3c) shown two strong peaks for $\mathrm{Pt} 4 \mathrm{f}_{7 / 2}(71.4 \mathrm{eV})$ and $\mathrm{Pt}$ $4 f_{5 / 2}(74.85 \mathrm{eV})$, indicated the presence of $\mathrm{Pt}(0)$ species. These Pt $4 \mathrm{f}$ peaks of $\mathrm{Pt}_{3} \mathrm{Ni}_{1} / \mathrm{Ni}_{x} \mathrm{Fe} \mathrm{LDHs}$ were lightly negative shifted about $0.2 \mathrm{eV}$ compared with that of $\mathrm{Pt} / \mathrm{Ni}_{\mathrm{x}} \mathrm{Fe} \mathrm{LDHs}$, which might be caused by the direct chemical interaction between $\mathrm{Ni}$ with $\mathrm{Pt}$ in the processing of $\mathrm{PtNi}$ alloy deposition. ${ }^{18}$ Previous studies have confirmed that this type of interaction could alter the electronic structure and electron density of metal catalysts, thus exhibiting superior catalytic performance. ${ }^{19,} 20$ Fig. $3 d$ shown the Fe $2 p$ XPS spectrum with no obviously changed in four NiFe LDHs, $\mathrm{Ni}_{x} \mathrm{Fe}$ LDHs, Pt/Ni $\mathrm{Fe}$ LDHs, and $\mathrm{Pt}_{3} \mathrm{Ni}_{1} / \mathrm{Ni}_{x} \mathrm{Fe}$ LDHs nanocomposites, the peak locations shifted were caused by the electron deficiency in NixFe structure. The 0 1s highresolution spectrum of $\mathrm{Pt}_{3} \mathrm{Ni}_{1} / \mathrm{Ni}_{x} \mathrm{Fe}$ LDHs nanocomposites (Fig. $\mathrm{S} 8 \mathrm{~b})$ revealed the presence of three different oxygen environments at the binding energy values, namely, metaloxide bond (530.1 eV), $\mathrm{M}^{2+}-\mathrm{OH}$ functionalities $(531.8 \mathrm{eV})$ and $\mathrm{M}^{3+}-\mathrm{OH}$ functionalities $(533.9 \mathrm{eV}$ ), which is resonated well with the earlier reports of nickel iron $\mathrm{LDHs}$ and hydroxide/oxyhydroxides. ${ }^{17}$ This observation was also consistent with our Raman spectra findings (Fig. S9), two characteristic Raman bands appeared around 485 and $567 \mathrm{~cm}^{-1}$ originated from $\mathrm{Fe}^{3+} / \mathrm{Ni}^{2+}-\mathrm{O}-\mathrm{Ni}^{2+}$ and $\mathrm{Fe}^{3+}-\mathrm{O}-\mathrm{Fe}^{3+}$ linkage bands, respectively, whereas the band located at $689 \mathrm{~cm}^{-1}$ was attributed to intercalated $\mathrm{CO}_{3}{ }^{2-}$, unveiling the presence of $\mathrm{NiFe}$ LDHs in the nanocomposite. ${ }^{7}$ Besides, the similar Raman spectrum of $\mathrm{Pt}_{3} \mathrm{Ni}_{1} / \mathrm{Ni}_{x} \mathrm{Fe} \mathrm{LDH}$ and $\mathrm{Ni}_{x} \mathrm{Fe} \mathrm{LDH}$, suggested that both strong alkali etching and the electrochemical alloying process did not affect the crystal structure of the sample, which is coincided with XRD test conclusion. The above analysis 

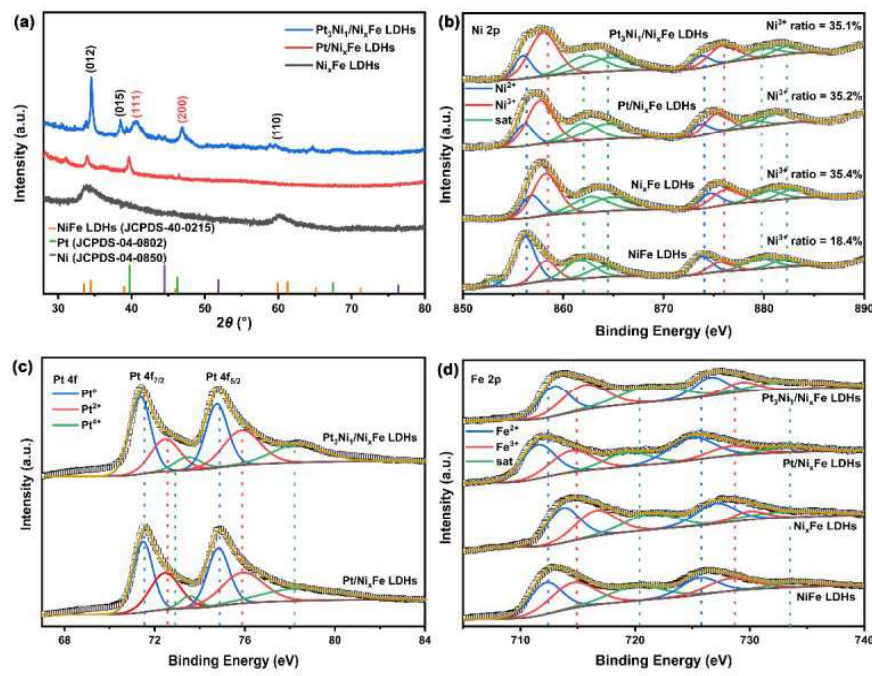

Fig. 3 (a) XRD patterns of $\mathrm{Ni}_{x} \mathrm{Fe} L \mathrm{LDH}$, $\mathrm{Pt} / \mathrm{Ni}_{\mathrm{X}} \mathrm{Fe} \mathrm{LDHs}$, and $\mathrm{Pt} \mathrm{NNi}_{3} / \mathrm{Ni}_{x} \mathrm{Fe} \mathrm{LDHs}$. High-resolution XPS spectra of (b) Ni 2p, (c) Pt 4f and (d) Fe 2p core levels in $\mathrm{Ni}_{x} \mathrm{Fe}$ LDHs, Pt/Ni $\mathrm{Fe}_{\mathrm{F}} \mathrm{LDH}$, and $\mathrm{Pt}_{3} \mathrm{Ni}_{1} / \mathrm{Ni}_{x} \mathrm{Fe}$ LDHs.

confirmed once again the formation of $\mathrm{Pt}_{3} \mathrm{Ni}_{1}$ alloys adhered to $\mathrm{Ni}_{x} \mathrm{Fe}$ LDHs nanosheets with the expected chemical nature.

The above characterizations indicated the successful uniform electrodeposition of ultra-small PtNi nanoparticles grown on defect-rich NiFe LDHs nanosheets on the $\mathrm{Ni}$ foam substrate. Although the construction of noble metal on the layered metal hydroxide sheets was rarely realized by the multi-step, timeand energy-consuming procedures, the fabrication of PtNi nanoalloy on NiFe LDHs has never been achieved. Notably, the synthesis proposed herein was performed without the need for high heat and pressure, any additional reducing agent, or organic solvent, which is quite different from previous studies in its cost-effective, feasibility and practicality. ${ }^{15}$ First, the hierarchical architectures of NiFe LDHs nanosheet arrays give rise to sufficient exposure of the active sites and facilitate fast mass transport. Second, the introduction of Ni vacancies in NiFe LDHs nanosheets can favourably adjust the surface electronic structure and orbital distributions, improve the electrical conductivity and also plays a critical role in the immobilization of PtNi nanoparticles. Meanwhile, the small-size effect of PtNi nanoparticles $\left(<10 \mathrm{~nm}\right.$ ) on $\mathrm{Ni}_{x} \mathrm{Fe}$ LDHs brings large specific surface area and reduce the interface resistance, enabling the desired electrocatalytic performance. Furthermore, the asmade "clean" surfaces of the PtNi/Ni $\mathrm{Fe}$ LDHs/NF electrode without the use of binders and conductive additives during the fabrication process, ensuring its intrinsic electrochemical activities.

To prove its potential for practical application, the independent $\mathrm{PtNi} / \mathrm{Ni}_{\mathrm{x}} \mathrm{Fe}$ LDHs/NF was directly used as working electrodes in alkaline solution to evaluate their ORR/OER performance. The OER activities of the $\mathrm{Pt}_{3} \mathrm{Ni}_{1} / \mathrm{Ni}_{x} \mathrm{Fe}$ LDHs, $\mathrm{Pt}_{1} \mathrm{Ni}_{1} / \mathrm{Ni}_{x} \mathrm{Fe} \mathrm{LDHs}$, $\mathrm{Pt}_{1} \mathrm{Ni}_{3} / \mathrm{Ni}_{x} \mathrm{Fe}$ LDHs, Pt/Ni $\mathrm{Fe}_{x}$ LDHs, $\mathrm{Ni}_{x} \mathrm{Fe}$ LDHs, NiFe LDHs, and the reference sample $20 \% \mathrm{Ir} / \mathrm{C}$-coated Ni foam with same massloading $\left(0.1 \mathrm{mg} \mathrm{cm}^{-2}\right)$ were evaluated in $1 \mathrm{M} \mathrm{KOH}$ by using (linear sweep voltammograms, LSVs) at a scan rate of $10 \mathrm{mV} \mathrm{s}^{-1}$ (Fig. 4a). The OER LSVs shown all of the as-prepared samples exhibited superior OER activity than commercial 20\% Ir/C catalyst, even upon the potential increasing to $1.8 \mathrm{~V}, \mathrm{Pt}_{3} \mathrm{Ni}_{1} /$ $\mathrm{Ni}_{x} \mathrm{Fe}$ LDHs achieves an extremely large current density of 207.8 $\mathrm{mA} \mathrm{cm}{ }^{-2}$, far exceeding that of the $20 \% \mathrm{Ir} / \mathrm{C}$ benchmark $(111.4$ $\mathrm{mA} \mathrm{cm}^{-2}$ ), and accompanied by the evolution of dense oxygen bubbles (Fig. S1Oa). Moreover, the $\mathrm{Pt}_{3} \mathrm{Ni}_{1} / \mathrm{Ni}_{x} \mathrm{Fe} \mathrm{LDH}$ s electrode exhibited the decent overpotentials at different current densities but also the smaller Tafel slope among the studied samples (Fig. $4 \mathrm{~b}-\mathrm{c}$ ), indicating its excellent activity and fast reaction kinetics for OER. The overpotential at $10 \mathrm{~mA} \mathrm{~cm}{ }^{-2}$ cannot be read out directly from the LSV curve due to the overlap of the anodized peak of $\mathrm{Ni}^{2+}$ ions around at $1.45 \mathrm{~V} .{ }^{13}, 21$ Thus, we estimated the overpotentials at $10 \mathrm{~mA} \mathrm{~cm}^{-2}$ roughly by extrapolating the polarization curves of all as-prepared samples (Fig S11). Furthermore, the electrochemical active surface area was calculated by the double-layer capacitance $\left(C_{\mathrm{dl}}\right)$, resulting $51,128,149,199,191$, and $168 \mathrm{~cm}^{2}$ for $\mathrm{NiFe}$ LDHs, $\quad \mathrm{Ni}_{x} \mathrm{Fe}$ LDHs, $\mathrm{Pt} / \mathrm{Ni}_{x} \mathrm{Fe}$ LDHs, $P t_{3} \mathrm{Ni}_{1} / \mathrm{Ni}_{x} \mathrm{Fe}$ LDHs, $\mathrm{Pt}_{1} \mathrm{Ni}_{1} / \mathrm{Ni}_{x} \mathrm{Fe} \mathrm{LDHs}$, and $\mathrm{Pt}_{1} \mathrm{Ni}_{3} / \mathrm{Ni}_{x} \mathrm{Fe}$ LDHs, respectively, which further interpreted that the adorned PtNi nanoalloys can expose more active sites to the electrolyte (Fig. S12). Simultaneously, the above experimental results also proved that introducing $\mathrm{Ni}^{2+}$ vacancies to $\mathrm{NiFe}$ LDHs nanosheets can efficiently enhance the OER performance of electrocatalysts. Apart from the high activity, $\mathrm{Pt}_{3} \mathrm{Ni}_{1} / \mathrm{Ni}_{x} \mathrm{Fe}$ LDHs also delivered considerable mass transportation and mechanical robustness toward OER. As depicted in Fig. 4d, the LSV curves of $\mathrm{Pt}_{3} \mathrm{Ni}_{1} / \mathrm{Ni}_{x} \mathrm{Fe}$ LDHs for OER shown slight degradation after 2000 successive $C V$ cycles between 1.02 and $1.82 \mathrm{~V}$ at $100 \mathrm{mV} \mathrm{s}^{-1}$, and the good catalytic stability was also proved again by multi-step chronopotentiometric analysis (Fig. S10b). We further tracked the electronic structure change for $\mathrm{Pt}_{3} \mathrm{Ni}_{1} / \mathrm{Ni}_{x} \mathrm{Fe}$ LDHs after OER stability test by XPS techniques. As shown in Fig. S13a, the highresolution XPS spectra of $\mathrm{Pt} 4 \mathrm{f}$ regions presented a major of high-active metallic state $\mathrm{Pt}\left(\mathrm{Pt}^{0}\right)$ with an increment oxidation state ratios after 2000 CV cycles stability test (Fig. S13a), which is ascribed to the chemisorption of surface oxygenated species $\left({ }^{*} \mathrm{OH}\right.$ and/or $\left.{ }^{*} \mathrm{O}\right)$ during the OER process. ${ }^{22}$ In addition, Ni species have been recognized as an active phase for the OER process, ${ }^{23}$ results showed that $\mathrm{PtNi} / \mathrm{Ni}_{x} \mathrm{Fe}$ LDHs exhibited the enhanced OER performance compared to that of $\mathrm{Pt} / \mathrm{Ni}_{x} \mathrm{Fe}$ LDHs (Fig. 4a). The high-resolution XPS spectra of $\mathrm{Ni} 2 p$ regions showed a drastic enhancement of $\mathrm{Ni}^{3+}$ proportions (60.0\%) after the 2000 CV cycles stability test (Fig. S13b), which was usually associated with the enhanced electrocatalytic activity. ${ }^{18}$ Thus, we speculated that the underlying $\mathrm{Ni}$ species in the $\mathrm{Pt}_{3} \mathrm{Ni}_{1} / \mathrm{Ni}_{x} \mathrm{Fe}$ LDHs catalysts play a critical role in catalyzing OER. The potential Ni phases in PtNi nanoparticles could help to promote OER on Pt probably by decelerating the oxidation of $\mathrm{Pt}$ thorough modifying the surface electronic structures (i.e., lowered dband centre). ${ }^{24}$ The $O$ 1s peak was slightly shifted to higher binding energies, which may be ascribed to the stronger absorption of $\mathrm{H}_{2} \mathrm{O}_{\text {ads }}$ during the OER process (Fig. S13c,). ${ }^{25}$ No obvious changes of Fe $2 p$ were observed before and after OER stability test and the $\mathrm{Fe}^{3+}$ ratio kept at $70.5 \%$ (Fig. S13d) near to that of initial $\mathrm{Pt}_{3} \mathrm{Ni}_{1} / \mathrm{Ni}_{x} \mathrm{Fe}$ LDHs catalyst (70.9\%). Moreover, we also probed the structural change for $\mathrm{Pt}_{3} \mathrm{Ni}_{1} / \mathrm{Ni}_{x} \mathrm{Fe}$ LDHs after long term stability test. As displayed in the TEM images (Fig. 
$\mathrm{S} 14)$, the $\mathrm{Pt}_{3} \mathrm{Ni}_{1}$ nanoparticles were well separated from each other without serious aggregation or oriented attachment, which further verified the significant immobilized effects of $\mathrm{Ni}$ vacancies on $\mathrm{Ni}_{x} \mathrm{Fe}$ LDHs surface. The HRTEM image exhibited a relatively intact crystal morphology accompanied by a slightly increased (111) crystal plane spacing of $0.232 \mathrm{~nm}$ (Fig. S14d), which might be attributed to the trace migration of interior $\mathrm{Ni}$ atoms to the surface during long-term electrocatalytic OER process. ${ }^{18,26}$

The ORR catalytic activities of $\mathrm{Pt}_{3} \mathrm{Ni}_{1} / \mathrm{Ni}_{x} \mathrm{Fe} \mathrm{LDHs}$ and comparative samples, including $\mathrm{Pt}_{1} \mathrm{Ni}_{1} / \mathrm{Ni}_{x} \mathrm{Fe}$ LDHs, $\mathrm{Pt}_{1} \mathrm{Ni}_{3} / \mathrm{Ni}_{x} \mathrm{Fe}$ LDHs, Pt/Ni $\mathrm{Ni}_{x} \mathrm{Fe}$ LDHs, $\mathrm{Ni}_{x} \mathrm{Fe}$ LDHs, and commercial Pt/C (coated on $\mathrm{Ni}$ foam) were tested in $\mathrm{O}_{2}$-saturated $0.1 \mathrm{M} \mathrm{KOH}$ electrolyte. All of the polarization curves consisted of typical two-stage linear regions, the diffusion-limiting current region at low overpotential and the mixed kinetic-diffusion control region at high overpotential. The LSV curves (Fig. 4e) demonstrated that $\mathrm{Pt}_{3} \mathrm{Ni}_{1} / \mathrm{Ni}_{x} \mathrm{Fe}$ LDHs had a higher ORR half-wave potential $\left(\mathrm{E}_{1 / 2}\right)$ of $0.852 \mathrm{~V}$, which is more positive than those of $\mathrm{Pt}_{1} \mathrm{Ni}_{1} / \mathrm{Ni}_{x} \mathrm{Fe} \mathrm{LDHs}$ $\left(E_{1 / 2}=0.84 \mathrm{~V}\right), \mathrm{Pt}_{1} \mathrm{Ni}_{3} / \mathrm{Ni}_{\mathrm{x}} \mathrm{Fe} \mathrm{LDHs}\left(\mathrm{E}_{1 / 2}=0.827 \mathrm{~V}\right), \mathrm{Pt} / \mathrm{Ni}_{\mathrm{x}} \mathrm{Fe}$ $\operatorname{LDHs}\left(\mathrm{E}_{1 / 2}=0.851 \mathrm{~V}\right)$, and comparable to commercial Pt $/ \mathrm{C}\left(\mathrm{E}_{1 / 2}=\right.$ $0.862 \mathrm{~V})$. The electrochemically active surface area (ECSA) toward ORR was also calculated, as shown in Fig S15, the $\mathrm{Pt}_{3} \mathrm{Ni}_{1} / \mathrm{Ni}_{x} \mathrm{Fe}$ LDHs exhibited the highest electrocatalytic activity with an ECSA of $89.3 \mathrm{~m}^{2} \mathrm{~g}^{-1}$, which was 1.73-, 1.2- and 4.7-fold of Pt/Ni $\mathrm{Ne}_{\mathrm{x}} \mathrm{LDHs}\left(51.8 \mathrm{~m}^{2} \mathrm{~g}^{-1}\right), \mathrm{Pt}_{1} \mathrm{Ni}_{1} / \mathrm{Ni}_{\mathrm{x}} \mathrm{Fe}$ LDHs $\left(73.1 \mathrm{~m}^{2} \mathrm{~g}^{-1}\right)$ and $\mathrm{Pt}_{1} \mathrm{Ni}_{3} / \mathrm{Ni}_{x} \mathrm{Fe}$ LDHs $\left(19 \mathrm{~m}^{2} \mathrm{~g}^{-1}\right.$ ) catalysts, respectively.
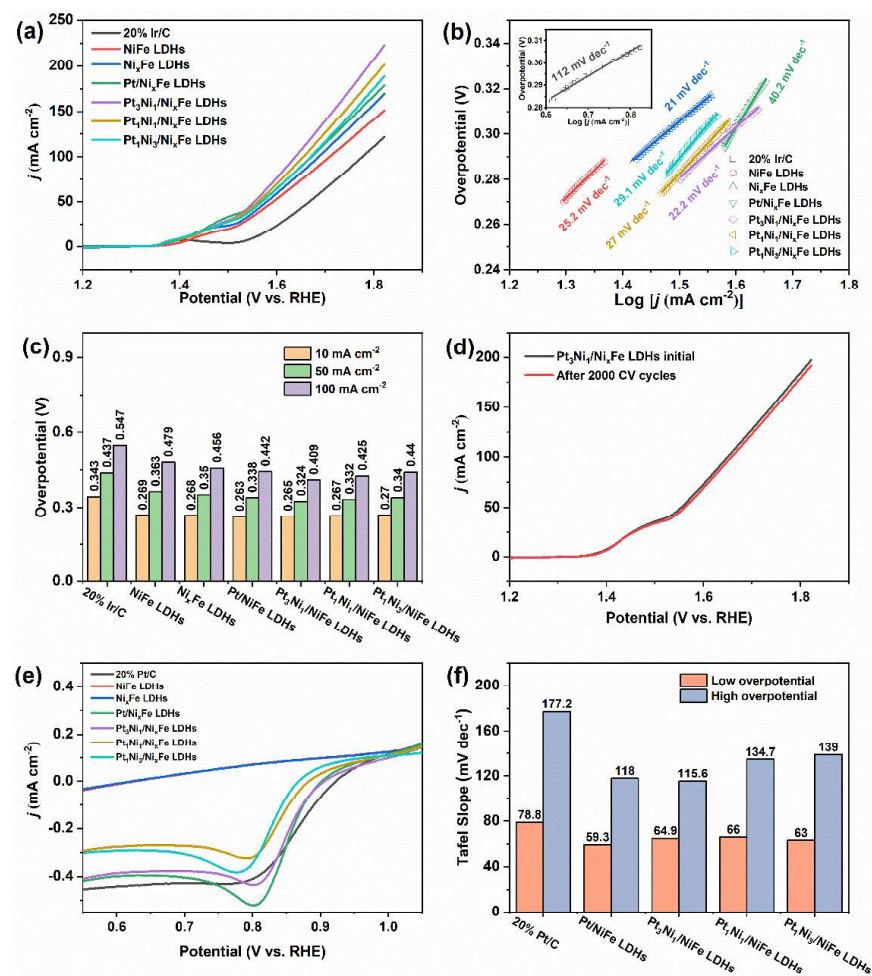

Fig. 4 (a) OER LSV curves of $\mathrm{Pt}_{3} \mathrm{Ni}_{1} / \mathrm{Ni}_{x} \mathrm{Fe}$ LDHs, $P t_{1} \mathrm{Ni}_{1} / \mathrm{Ni}_{x} \mathrm{Fe}$ LDHs, $\mathrm{Pt}_{1} \mathrm{Ni}_{3} / \mathrm{Ni}_{x} \mathrm{Fe}$ LDHs, Pt/Ni $\mathrm{Ni}_{x} \mathrm{Fe}$ LDHs, $\mathrm{Ni}_{x} \mathrm{Fe}$ LDHs, NiFe LDHs and commercial $20 \% \mathrm{Ir} / \mathrm{C}$, the corresponding (b) Tafel plots, and (c) overpotentials at different current density. (d) OER stability performance of $\mathrm{Pt}_{3} \mathrm{Ni}_{1} / \mathrm{Ni}_{x} \mathrm{Fe}$ LDHs. (e) ORR LSV curves of as-made samples and commercial $20 \% \mathrm{Pt} / \mathrm{C}$. (f) ORR Tafel slope values at low and high overpotential regions of various catalysts.
However, $\mathrm{Ni}_{x} \mathrm{Fe}$ LDHs and NiFe LDHs electrodes shown interior ORR performance, which signified the enhanced ORR performance by modulation of electronic and catalytic properties with anchoring $\mathrm{Pt}$ and/or Pt alloys elements on $\mathrm{Ni}_{\mathrm{x}} \mathrm{Fe}$ LDHs. Tafel slopes (Fig. $4 \mathrm{f}$ and S16, Supporting Information) were obtained from the linear plots of LSV data to assess the kinetic properties of ORR. The as-prepared $\mathrm{Pt}_{3} \mathrm{Ni}_{1} / \mathrm{Ni}_{x} \mathrm{Fe}$ LDHs demonstrated both the relatively small Tafel slope value at low and high overpotential regions, thus possessing a faster electron transfer and a more efficient reactant diffusion. Stability is also an important index for evaluating the electrochemical properties of the electrocatalyst. The $\mathrm{Pt}_{3} \mathrm{Ni}_{1} / \mathrm{Ni}_{x} \mathrm{Fe}$ LDHs exhibited significant stable electrocatalytic activity and durability toward ORR. As displayed in Fig. S17a, ORR LSV curves for $\mathrm{Pt}_{3} \mathrm{Ni}_{1} / \mathrm{Ni}_{x} \mathrm{Fe}$ LDHs shown a slightly negative shift of $2 \mathrm{mV}$ after continuous $2000 \mathrm{CV}$ cycles. Meanwhile, the chronoamperometric response displayed a negligible decrease in current density under more than $20 \mathrm{~h}$ (Fig. S17b). The enhanced ORR activity of $\mathrm{Pt}_{3} \mathrm{Ni}_{1} / \mathrm{Ni}_{x} \mathrm{Fe}$ LDHs was attributed to the well-known downshift of the Pt d-band center energy after alloying with transition metals, which would weaken the bonding strength of $\mathrm{Pt}-\mathrm{O}$ species and lead to an accelerated ORR kinetics. ${ }^{16}$ After the ORR durability test, the incremental of $\mathrm{Pt}^{2+}$ and $\mathrm{Pt}^{4+}$ ratios were observed in $\mathrm{Pt} 4 \mathrm{f}$ signals because of the affinity to surface oxygen (Fig. S18a). Additionally, we found that $\mathrm{Ni}$ oxidation state delivered an upward trend compared to the initial catalyst ( $45.2 \%$ vs. $35.1 \%$, Fig. S18b). The XPS spectra of $\mathrm{O} 1 \mathrm{~s}$ indicated strong metal-O and $\mathrm{H}_{2} \mathrm{O}$ ads absorption peaks (Fig. S18c), while the chemical state of $\mathrm{Fe}\left(\mathrm{Fe}^{3+}:\right.$ 70.4\%) did not change significantly during the ORR process (Fig. S18d). Previous studies revealed the large difference of oxygen binding energies between Pt and $\mathrm{Ni}(\mathrm{Ni}: 0.34 \mathrm{eV}, \mathrm{Pt}: 1.57 \mathrm{eV}),{ }^{27}$ thus oxygen species were more preferred to bind with the $\mathrm{Ni}$, which was also verified by the DFT calculations in Fig 5 . It was reported that Pt bimetallic catalysts suffer from unstable ORR activity as strong interaction between $\mathrm{Ni}$ and oxygen species causes the surface $\mathrm{Ni}$ atoms dissolved out, leading to the destruction of nanostructures. ${ }^{28}$ Surprisingly, negligible structural changes were observed after the stability tests (Fig. S19), the small $\mathrm{Pt}_{3} \mathrm{Ni}_{1}$ nanoparticles $(<10 \mathrm{~nm})$ were individually and uniformly distributed on the $\mathrm{Ni}_{x} \mathrm{Fe}$ LDHs skeleton and the increased interplanar distance $(0.231 \mathrm{~nm})$ caused by the surface segregation of $\mathrm{Ni}$ atoms. ${ }^{24}$ Several studies reported that the size effect was an important parameter for the stability of Pttransition metal species, and smaller particle size could efficiently reduce transition metal atoms leaching from the catalysts. ${ }^{20}$ Therefore, we speculated the potential Ni species promote the adsorption of oxygen molecules and decrease the adsorption of other oxygen species on Pt. Based on the above analysis, we proposed the synergistic effects of cation defects, incorporation of $\mathrm{Ni}$, and the appropriate $\mathrm{Pt} / \mathrm{Ni}$ ratio provide a proper metal-oxygen binding strength and the excellent electrocatalytic stability for $\mathrm{Pt}_{3} \mathrm{Ni}_{1} / \mathrm{Ni}_{x} \mathrm{Fe}$ LDHs. The ORR/OER performance of the above samples presents comparable to some previously reported NiFe LDHs electrocatalysts (Table S1). In short, the remarkable ORR/OER performance and freestanding features make $\mathrm{Pt}_{3} \mathrm{Ni}_{1} / \mathrm{Ni}_{x} \mathrm{Fe}$ LDHs as an attractive 
bifunctional catalyst fabricated in the air electrode for rechargeable fuel cells and metal-air batteries.

Obviously, the good catalytic performance of $\mathrm{Pt}_{3} \mathrm{Ni}_{1} / \mathrm{Ni}_{x} \mathrm{Fe} \mathrm{LDHs}$ was attributed to the formation of uniform Pt-based NPs via $\mathrm{Ni}^{2+}$ vacancies on the surface of $\mathrm{Ni}_{x} \mathrm{Fe} \mathrm{LDHs}$, which ensures sufficient electrochemical active sites for ORR/OER performance. For comparison, $\mathrm{Pt}$ and $\mathrm{Pt}_{3} \mathrm{Ni}_{1}$ NPs were deposited on the perfect $\mathrm{NiFe}$ LDHs material under the same conditions as that of $\mathrm{Ni}_{x} \mathrm{Fe}$ LDHs. As shown in Fig. S20 and S21, sparse Pt and $\mathrm{Pt}_{3} \mathrm{Ni}_{1}$ NPs, and even clustered NPs were formed on NiFe LDHs due to their high surface free energy. Notably, $\mathrm{Ni}^{2+}$ vacancies served as important anchor sites for the in situ growth of $\mathrm{Pt}$ and $\mathrm{Pt}_{3} \mathrm{Ni}_{1}$ NPs. The electrocatalytic performance was recorded by a potential cycling test at 0.164-1.76 V (vs. RHE) in $0.1 \mathrm{M} \mathrm{O}_{2^{-}}$ saturated $\mathrm{KOH}$ solution. Both $\mathrm{Pt} / \mathrm{Ni}_{x} \mathrm{Fe}$ LDHs and $\mathrm{Pt}_{3} \mathrm{Ni}_{1} / \mathrm{Ni}_{x} \mathrm{Fe}$ LDHs catalysts (Fig. S22) exhibited excellent durability after 2000 successive CV cycles, whereas the Pt/NiFe LDHs and $\mathrm{Pt}_{3} \mathrm{Ni}_{1} / \mathrm{NiFe}$ LDHs showed obvious degradation in polarization curves. The peaks around at 1.2-1.3 $\mathrm{V}$ were attributed to the reduction of $\mathrm{Ni}^{3+}$ ions. ${ }^{29}$ This visible difference indicated that $\mathrm{Ni}^{2+}$ vacancies have a stronger interaction with Pt-based NPs, which is consistent with the previous studies. ${ }^{13}$

The above experimental results demonstrated that the existence of $\mathrm{Pt}_{3} \mathrm{Ni}_{1}$ nanoparticles anchored $\mathrm{Ni}_{x} \mathrm{Fe}$ LDHs enhanced the OER/ORR catalytic performance compared with both the pristine $\mathrm{Ni}_{x} \mathrm{Fe} \mathrm{LDH}$ and Pt nanoparticles loaded $\mathrm{Ni}_{\mathrm{x}} \mathrm{Fe}$ LDHs. To gain insight into the inherent relationship between the electronic structure and the outstanding ORR/OER mechanisms of $\mathrm{Ni}_{x} \mathrm{Fe}$ LDHs with different PtNi alloy nanoparticle, spinpolarized density functional theory (DFT) calculations were performed on model structure (computational details are shown in the Theoretical Calculations). Based on previous studies that the $3 \times 3$ supercells $\mathrm{Ni}_{x} \mathrm{Fe}$ LDHs with three $\mathrm{Ni}$ vacancies ( $\mathrm{Ni}_{x} \mathrm{Fe} \mathrm{LDHs}$ ) were constructed (Fig. 5a). ${ }^{10}$ Another study also demonstrated that $\mathrm{Ni}^{2+}$ vacancies play a vital role in the stabilizing of Pt nanoparticles. ${ }^{15}$ Therefore, we anchored $\mathrm{Pt}$ (Fig. 5b) and $\mathrm{Pt}_{3} \mathrm{Ni}_{1}$ (Fig. 5c) nanoparticles on the Ni vacancies of $\mathrm{Ni}_{x} \mathrm{Fe} \mathrm{LDHs}$ as theoretical models to simulate the experimentally obtained material.

Control theoretical calculations were first performed to validate the active catalytic sites for OER of $\mathrm{Pt}_{3} \mathrm{Ni}_{1} / \mathrm{Ni}_{x} \mathrm{Fe}$ LDHs in alkaline condition (for details, see Theoretical Calculations Section). Two adsorption sites including Ni-top (Fig. 5c) and Pt-Pt hollow site (Fig. S23) of $\mathrm{Pt}_{3} \mathrm{Ni}_{1} / \mathrm{Ni}_{x} \mathrm{Fe} \mathrm{LDHs}$ were considered, respectively. Fig. $5 d$ and S14a displayed the calculated free energy pathways of the four-electron OER reaction processes, it was obvious that the largest free energy change $(\triangle \mathrm{G})$ in the ${ }^{*} \mathrm{OOH}$ formation step was the sluggish rate-determining step (RDS step) for both Ni-top (Fig. 5f) and Pt-Pt hollow sites (Fig. S23a) of $\mathrm{Pt}_{3} \mathrm{Ni}_{1} / \mathrm{NiFe}$ LDHs. Compared to Pt-Pt hollow site, Ni-top site of $\mathrm{Pt}_{3} \mathrm{Ni}_{1} / \mathrm{Ni}_{x} \mathrm{Fe}$ LDHs showed much lower $\triangle \mathrm{G}{ }_{\mathrm{OOH}}(1.55 \mathrm{~V})$ at the applied voltage $U=0 \mathrm{~V}$, and even at $U=1.23 \mathrm{~V}(0.32 \mathrm{~V})$. Moreover, these values were also less than the calculated results on Pt-top site

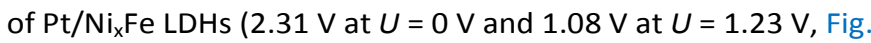
$5 \mathrm{~d})$. The above DFT calculations not only revealed Ni-top of $\mathrm{Pt}_{3} \mathrm{Ni}_{1} / \mathrm{NiFe}$ LDHs as active OER site but also suggested superior OER catalytic activity of PtNi alloy than single Pt metals, further confirmed that the introduction of $\mathrm{Ni}$ to $\mathrm{Pt}$ can reduce the cost and improve catalytic performance simultaneously. Meanwhile, the free energetics of the four-electron ORR reaction process on $\mathrm{Pt}_{3} \mathrm{Ni}_{1} / \mathrm{Ni}_{x} \mathrm{Fe}$ LDHs and $\mathrm{Pt} / \mathrm{Ni}_{x} \mathrm{Fe}$ LDHs catalysts was also investigated. The free-energy paths of ORR were shown in Fig. $5 e$ and $g$, the ORR electron transfer steps cannot be carried out spontaneously at the equilibrium potential (1.23 V) on both $\mathrm{Pt}_{3} \mathrm{Ni}_{1} / \mathrm{Ni}_{x} \mathrm{Fe}$ LDHs and $\mathrm{Pt} / \mathrm{Ni}_{\mathrm{x}} \mathrm{Fe}$ LDHs active sites. For $\mathrm{Pt}_{3} \mathrm{Ni}_{1} / \mathrm{Ni}_{x} \mathrm{Fe}$ LDHs (Fig. $5 \mathrm{~g}$ ), the free-energy pathway became downhill and the ORR reaction can be generated spontaneously with the overpotential $(n)$ decreased to $0.78 \mathrm{~V}$, yielding a minimum ORR overpotential of $0.45 \mathrm{~V}$, while $\eta=1.23 \mathrm{~V}$ at $U=0$ $\mathrm{V}$ on $\mathrm{Pt} / \mathrm{Ni}_{x} \mathrm{Fe} \mathrm{LDHs}$ (Fig. 5e). It can be implied that enhanced ORR performance of $\mathrm{Pt}_{3} \mathrm{Ni}_{1} / \mathrm{Ni}_{x} \mathrm{Fe}$ LDHs was related to the mechanism of easier desorption of ${ }^{*} \mathrm{O}$ and ${ }^{*} \mathrm{OH}$. Previous DFT study has shown that the ORR/OER catalytic activities were correlated to weak adsorbates adsorption energy when the rate-determining steps occurred on the fourth reaction step (the reduction of ${ }^{*} \mathrm{OH}$ to $\mathrm{OH}^{-}(\mathrm{I})$, Equation $1 \mathrm{~d}$ ) for ORR and the third reaction step (the oxidation of ${ }^{*} \mathrm{O}$ to ${ }^{*} \mathrm{OOH}$ species) for OER, respectively. ${ }^{30}$ Therefore, we calculated the adsorption energy $\left(\Delta \mathrm{E}_{\mathrm{ads}}\right)$ for ${ }^{*} \mathrm{OH},{ }^{*} \mathrm{O}$ and ${ }^{*} \mathrm{OOH}$ intermediates adsorbed on Ni top site of $\mathrm{Pt}_{3} \mathrm{Ni} / \mathrm{Ni}_{x} \mathrm{Fe}$ LDHs (Fig. S24a) and Pt top site of $\mathrm{Pt} / \mathrm{Ni}_{\mathrm{x}} \mathrm{Fe}$ LDHs (Fig. S24b) nanosheets, respectively (See Table S2 in details). Notably, all intermediates showed lower adsorption energy on $\mathrm{Ni}$ top site of $\mathrm{Pt}_{3} \mathrm{Ni}_{1} / \mathrm{Ni}_{x} \mathrm{Fe}$ LDHs nanosheets compared with $\mathrm{Pt}$ top site of $\mathrm{Pt} / \mathrm{Ni}_{x} \mathrm{Fe} \mathrm{LDHs}$, which implied weaker adsorption on the $\mathrm{Ni}$ top site. Additionally, difference charge density results shown that a strong interaction between intermediates and top-Ni atom for $\mathrm{Pt}_{3} \mathrm{Ni}_{1} / \mathrm{Ni}_{x} \mathrm{Fe}$ LDHs nanosheets (Fig. S25). Hence, the low overpotential of $\mathrm{Pt}_{3} \mathrm{Ni}_{1} / \mathrm{Ni}_{x} \mathrm{Fe} \mathrm{LDHs}$ was probably caused by the weak adsorption of adsorbates on the active sites.

To further understand the electronic properties of pristine $\mathrm{Ni}_{x} \mathrm{Fe}$ LDHs, Pt/Ni $\mathrm{Ni}_{\mathrm{F}} \mathrm{Fe} \mathrm{LDHs}$, and $\mathrm{Pt}_{3} \mathrm{Ni}_{1} / \mathrm{Ni}_{\mathrm{x}} \mathrm{Fe}$ LDHs, the density of

(a)

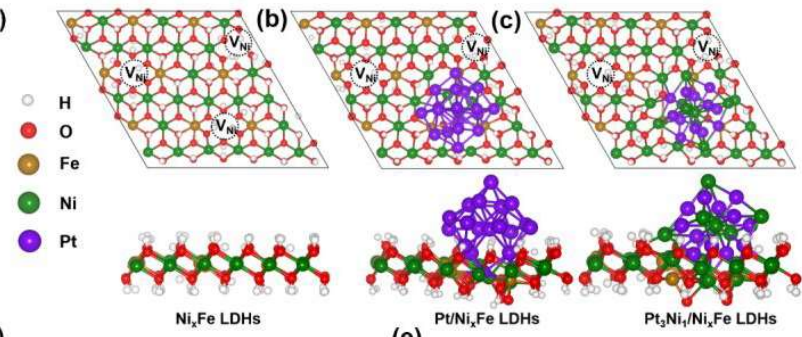

(d)

(e)

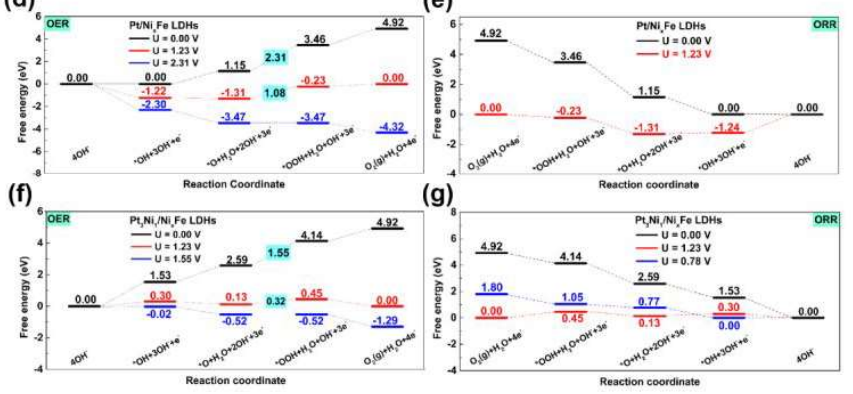

Fig. 5 Top and side views of optimized geometries of (a) $\mathrm{Ni}_{x} \mathrm{Fe}$ LDHs, (b) Pt/ $\mathrm{Ni}_{x} \mathrm{Fe}$ LDHs and (c) $\mathrm{Pt}_{3} \mathrm{Ni}_{1} / \mathrm{Ni}_{x} \mathrm{Fe}$ LDHs. The white, red, brown, green and purple balls represent $\mathrm{H}, \mathrm{O}, \mathrm{Fe}, \mathrm{Ni}$ and $\mathrm{Pt}$ atoms, respectively. (d-g) The free energy profile for the OER and ORR pathway. 
states (DOS) were calculated and compared. As shown in Fig S26, defective $\mathrm{Ni}_{x} \mathrm{Fe}$ LDHs were semiconducting with a noticeable bandgap (nearly $0.30 \mathrm{eV}$ ) at the Fermi level in both spin-up and spin-down channels, while the absence of bandgap of $\mathrm{Pt}$ cluster and $\mathrm{Pt}_{3} \mathrm{Ni}_{1}$ alloy anchored $\mathrm{Ni}_{x} \mathrm{Fe} \mathrm{LDHs}$ result in the improved conductivity. However, the peak intensity was weaker for $\mathrm{Pt}_{3} \mathrm{Ni}_{1} / \mathrm{Ni}_{\mathrm{x}} \mathrm{Fe}$ LDHs compared with $\mathrm{Pt} / \mathrm{Ni}_{\mathrm{x}} \mathrm{Fe}$ LDHs at the Fermi level. The weaker peak intensity indicated that there is less electron occupation, which implied the weaker adsorption of adsorbates on the active sites, in good agreement of the Table S2 and Fig. S25, leading to the enhanced OER/ORR catalytic activity of $\mathrm{Pt}_{3} \mathrm{Ni}_{1} / \mathrm{Ni}_{x} \mathrm{Fe}$ LDHs.

To elucidate the practical applicability, HSABs assembled using metallic $\mathrm{Na}$ as the anode immersed in $1 \mathrm{M} \mathrm{NaClO}_{4}$ in TEGDME organic electrolyte, NASICON solid electrolyte as the separator, $\mathrm{O}_{2}$-saturated $0.1 \mathrm{M} \mathrm{NaOH}$ aqueous as the aqueous electrolyte, $\mathrm{Pt}_{3} \mathrm{Ni}_{1} / \mathrm{Ni}_{x} \mathrm{Fe} \mathrm{LDHs}, 20 \% \mathrm{Pt} / \mathrm{C}$, and $\mathrm{RuO}_{2}$ loaded on $\mathrm{Ni}$ foam as the cathode (Fig. 1a). During the discharge process, the Na metal on the anode side is oxidized to $\mathrm{Na}^{+}$and moves into the $\mathrm{NaOH}$ aqueous through the NASICON separator, and the ORR simultaneously occurs at the cathode. On charging, the $\mathrm{Na}^{+}$ions were transported from the aqueous electrolyte into the anode chamber and reduced to metallic $\mathrm{Na}$, together with the concurrent OER at the cathode side.

The initial charge-discharge voltage profiles of the cells using different electrocatalysts were investigated by galvanostatic charge-discharge processes. As shown in Fig. S27a, the battery assembled with the $\mathrm{Pt}_{3} \mathrm{Ni}_{1} / \mathrm{Ni}_{x} \mathrm{Fe}$ LDHs catalyst exhibited a high
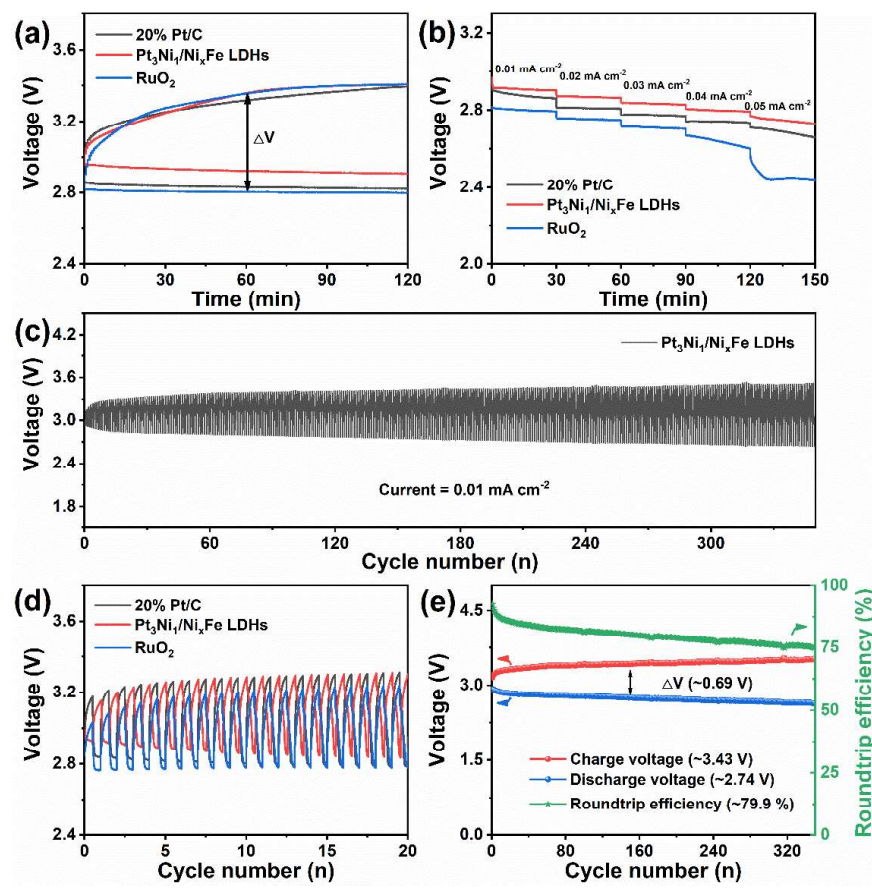

Fig. 6 (a) Charge-discharge curves of HSABs using $\mathrm{Pt}_{3} \mathrm{Ni}_{1} / \mathrm{Ni}_{x} \mathrm{Fe} \mathrm{LDHs,} \mathrm{Pt/C} \mathrm{and}$ $\mathrm{RuO}_{2}$ as anode catalyst at a current density of $0.01 \mathrm{~mA} \mathrm{~cm}{ }^{-2}$. (b) Discharge voltage curves of HSABs using different catalysts at different current densities. (c) Cycling stability of HSABs using $\mathrm{Pt}_{3} \mathrm{Ni}_{1} / \mathrm{Ni}_{x} \mathrm{Fe} \mathrm{LDH}$ at a current density of $0.01 \mathrm{~mA} \mathrm{~cm} \mathrm{~cm}^{-2}$ for 300 cycles. (d) Comparison of voltage the electrocatalyst with $\mathrm{Pt}_{3} \mathrm{Ni}_{1} / \mathrm{Ni}_{x} \mathrm{Fe} \mathrm{LDHs}$ and $\mathrm{Pt} / \mathrm{C}$ catalysts at $0.01 \mathrm{~mA} \mathrm{~cm}{ }^{-2}$ for initial 20 cycles. (e) The terminal voltages, overpotential gap $(\Delta \mathrm{V})$ and roundtrip efficiency during cycling of HSABs using $\mathrm{Pt}_{3} \mathrm{Ni}_{1} / \mathrm{Ni}_{x} \mathrm{Fe} \mathrm{LDHs}$. and stable open-circuit voltage of $3.07 \mathrm{~V}$, which was almost near the standard voltage of $3.11 \mathrm{~V}, 3,31,32$ compared to that involving $\mathrm{Pt}_{1} \mathrm{Ni}_{1} / \mathrm{Ni}_{x} \mathrm{Fe}$ LDHs (3.10 V), $\mathrm{Pt}_{1} \mathrm{Ni}_{3} / \mathrm{Ni}_{x} \mathrm{Fe}$ LDHs, (2.99 $\mathrm{V}$ ) and $\mathrm{Pt} / \mathrm{Ni}_{x} \mathrm{Fe}$ LDHs $(3.05 \mathrm{~V})$, suggesting its preeminent ORR performance. Notably, the HSAB assembled with the $\mathrm{Pt}_{3} \mathrm{Ni}_{1} / \mathrm{Ni}_{x} \mathrm{Fe}$ LDHs electrode retained a remarkably discharge/charge voltage of 2.91/3.41 $\mathrm{V}$ after $2 \mathrm{~h}$ under a current density of $0.01 \mathrm{~mA} \mathrm{~cm}^{-2}$, and with a decent round trip efficiency of $85.4 \%$ (Fig 6a). In contrast, the discharge/charge voltage of commercial $20 \% \mathrm{Pt} / \mathrm{C}(2.82 / 3.39 \mathrm{~V})$ and $\mathrm{RuO}_{2}$ catalysts $(2.80 / 3.41 \mathrm{~V})$, with corresponding round trip efficiencies of $83 \%$ and $82.2 \%$, respectively. It is well-known that the sluggish kinetics of the OER/ORR reactions at the cathode side is the main cause of the large voltage gap $(\Delta \mathrm{V}) .^{33}$ The battery using the $\mathrm{Pt}_{3} \mathrm{Ni}_{1} / \mathrm{Ni}_{x} \mathrm{Fe}$ LDHs catalyst displayed the narrowest $\Delta \mathrm{V}$ of $0.50 \mathrm{~V}$, compared to that of $\mathrm{Pt}_{1} \mathrm{Ni}_{1} / \mathrm{Ni}_{x} \mathrm{Fe} \mathrm{LDHs}$ (0.57 V, Fig. S27b), $\mathrm{Pt}_{1} \mathrm{Ni}_{3} / \mathrm{Ni}_{x} \mathrm{Fe}$ LDHs, (0.74 V, Fig. S27b), $\mathrm{Pt} / \mathrm{Ni}_{x} \mathrm{Fe}$ LDHs (0.56 V, Fig. S27b), Pt/C (0.57 V, Fig. 6a) and $\mathrm{RuO}_{2}$ (0.61 V, Fig. 6a), revealing excellent bifunctional ORR and OER catalytic performance. Fig. 6b shown the discharge curves of HSABs at various current densities, the discharge platform decreases with increasing the current densities for both the tested air electrodes. Among them, $\mathrm{Pt}_{3} \mathrm{Ni}_{1} / \mathrm{Ni}_{\mathrm{x}} \mathrm{Fe}$ LDHs electrode exhibited higher discharge voltages and relatively stable discharge performances, indicating the better ORR performance and superior stability of the binder-free electrode structure. As a result, the HSAB with the $\mathrm{Pt}_{3} \mathrm{Ni}_{1} / \mathrm{Ni}_{x} \mathrm{Fe}$ LDHs electrode displayed a better charge-discharge profile, with a low overpotential gap and high round trip efficiency, suggesting superior electrocatalytic activity of $\mathrm{Pt}_{3} \mathrm{Ni}_{1} / \mathrm{Ni}_{x} \mathrm{Fe}$ LDHs toward OER and ORR.

The cyclability of the battery is another crucial characteristic for practical applications. Fig. $6 \mathrm{c}$ presented the cycling performance of the HSABs with $\mathrm{Pt}_{3} \mathrm{Ni}_{1} / \mathrm{Ni}_{x} \mathrm{Fe}$ LDHs electrode that was measured at $0.01 \mathrm{~mA} \mathrm{~cm}^{-2}$. In comparison, $\mathrm{HSABs}$ with $20 \% \mathrm{Pt} / \mathrm{C}$, no significant polarization or drop of the $\mathrm{Pt}_{3} \mathrm{Ni}_{1} / \mathrm{Ni}_{x} \mathrm{Fe}$ LDHs cathode occurred after continuous 350 cycles (near to 117 h, Fig. $6 \mathrm{c}$ and S28). As given in Fig. $6 \mathrm{~d}, \mathrm{HSAB}$ with $\mathrm{Pt}_{3} \mathrm{Ni}_{1} / \mathrm{Ni}_{x} \mathrm{Fe}$ LDHs displayed smaller variations in the charge and discharge platforms during the initial 20 cycles compared to the referential $\mathrm{HSABs}$ with $20 \% \mathrm{Pt} / \mathrm{C}$ and $\mathrm{RuO}_{2}$ on $\mathrm{Ni}$ foam as the cathode. Based on the results of discharge voltage, HSAB with $\mathrm{Pt}_{3} \mathrm{Ni}_{1} / \mathrm{Ni}_{\mathrm{x}} \mathrm{Fe}$ LDHs cathode exhibited a better oxygen electrocatalytic performance than that with a benchmark $20 \%$ $\mathrm{Pt} / \mathrm{C}$ and $\mathrm{RuO}_{2}$ catalysts. The changes in the terminal charge/discharge voltage values and the round trip efficiency of the HSAB with $\mathrm{Pt}_{3} \mathrm{Ni}_{1} / \mathrm{Ni}_{x} \mathrm{Fe}$ LDHs cathode at each cycle were plotted in Fig. 6e. The average charge and discharge plateaux were $\sim 3.43$ and $\sim 2.74 \mathrm{~V}$, respectively, yielding a low $\Delta \mathrm{V}$ of 0.69 $V$ and a high round trip efficiency of $79.9 \%$, which is superior to other reported HSABs (Table S3). The remarkable cycling durability and rechargeability of the battery can be attributed to the efficient active sites of PtNi alloy and high conductivity of defect-rich $\mathrm{Ni}_{x} \mathrm{Fe}$ LDHs. Moreover, the catalyst feature after long term cycling was observed by SEM (Fig. S29), the negligible morphology change further displayed the excellent structure stability of $\mathrm{Pt}_{3} \mathrm{Ni}_{1} / \mathrm{Ni}_{x} \mathrm{Fe}$ LDHs. 


\section{Conclusions}

In summary, we reported a facile strategy to prepare $\mathrm{Pt}_{3} \mathrm{Ni}_{1} / \mathrm{Ni}_{x} \mathrm{Fe}$ LDHs as a binder-free catalytic electrode for HSABs. The HSAB with $\mathrm{Pt}_{3} \mathrm{Ni}_{1} / \mathrm{Ni}_{x} \mathrm{Fe} \mathrm{LDH}$ s cathode delivered a higher open circle potential of $2.98 \mathrm{~V}$ and a lower $\Delta \mathrm{V}$ of $0.50 \mathrm{~V}$ together with remarkable cycling stability and excellent rechargeability with an average high round trip efficiency of $79.9 \%$ during 350 cycles, which outperforms the HSABs assembled with the commercial catalyst composed of $\mathrm{Pt} / \mathrm{C}$ and $\mathrm{RuO}_{2}$. The remarkable charge-discharge performance and long-term cycling stability are mainly ascribed to the following reasons: (1) the abundant $\mathrm{Ni}^{2+}$ vacancies alters the surface electronic structure of NiFe LDHs, which promotes electron/ion transfer kinetics and induces the strong interaction with $\mathrm{PtNi}$ nanoalloys; (2) the uniformly dispersed ultrafine PtNi nanoparticles on $\mathrm{Pt}_{3} \mathrm{Ni}_{1} / \mathrm{Ni}_{x} \mathrm{Fe}$ LDHs enhance the electronic conductivity and provide abundant catalytic active sites, thus greatly boost ORR and OER in an alkaline medium; (3) the 3D hierarchically porous architectures of $\mathrm{Pt}_{3} \mathrm{Ni}_{1} / \mathrm{Ni}_{x} \mathrm{Fe} \mathrm{LDHs}$ offers high integrity and durability, high accessibility for electroactive sites, and enhances interfacial kinetics that facilitates media transfer, as well as prevent catalytic by-product aggregation; (4) the binder-free design conducive to exposing more active sites, leading a good catalytic performance. Thus, we believe that the discovery of the bifunctional $\mathrm{Pt}_{3} \mathrm{Ni}_{1} / \mathrm{Ni}_{\mathrm{x}} \mathrm{Fe}$ LDHs electrocatalyst sheds new light on the rational design of high-performance binder-free catalytic electrodes for large-scale application in energy conversion and storage.

\section{Experimental Section}

Synthesis of NiFe Layered Double Hydroxides (NiFe LDHs), NiZnFe Layered Double Hydroxides (NiZnFe LDHs) nanosheets

The $\mathrm{M}^{2+}$-Fe LDHs ( $\mathrm{M}=\mathrm{Ni}, \mathrm{Zn}$ ) nanosheets were prepared using a facile electrosynthesis method. Typically, nickel foam (NF, $10 \times 30 \times 0.05 \mathrm{~mm}^{3}$ ) was sonicated in $2 \mathrm{M} \mathrm{HCl}$ solution for $15 \mathrm{~min}$ and rinsed subsequently with water and ethanol to ensure a clean surface. The electrodeposition was carried out in a standard three-electrode system cell containing NF as the working electrode, Pt plate as the counter electrode and $\mathrm{Ag} / \mathrm{AgCl}(3 \mathrm{M} \mathrm{KCl})$ as the reference electrode, respectively. The electrolyte for the electrosynthesis of NiFe-LDH was contained $\mathrm{Ni}\left(\mathrm{NO}_{3}\right)_{2} \cdot 6 \mathrm{H}_{2} \mathrm{O}(0.03 \mathrm{M})$ and $\mathrm{Fe}\left(\mathrm{NO}_{3}\right)_{3} \cdot 9 \mathrm{H}_{2} \mathrm{O}(0.01 \mathrm{M})$. The total cation concentration in the electrolyte was maintained at 0.04 $\mathrm{M}$. The potentiostatic deposition then carried out at $-1.0 \mathrm{~V}$ vs. $\mathrm{Ag} / \mathrm{AgCl}$ for 300 s at room temperature. The obtained NiFe-LDH nanosheets were carefully withdrawn and rinsed thoroughly with water and ethanol, left dried at $45{ }^{\circ} \mathrm{C}$. The NiZnFe LDHs nanosheets were prepared via a similar method, by replacing $\mathrm{Ni}\left(\mathrm{NO}_{3}\right)_{2} \cdot 6 \mathrm{H}_{2} \mathrm{O}(0.03 \mathrm{M})$ with a mixture of $\mathrm{Ni}\left(\mathrm{NO}_{3}\right)_{2} \cdot 6 \mathrm{H}_{2} \mathrm{O}(0.027$ $\mathrm{M})$ and $\mathrm{Zn}\left(\mathrm{NO}_{3}\right)_{2} \cdot 6 \mathrm{H}_{2} \mathrm{O}(0.003 \mathrm{M})$.

\section{Synthesis of $\mathrm{Ni}_{\mathbf{x}} \mathrm{Fe}$ LDHs nanosheets}

The introduce of $\mathrm{Ni}^{2+}$ vacancies in $\mathrm{Ni}_{x} \mathrm{Fe}$ nanosheets was based on the reported method with slight modification. ${ }^{10}$ Briefly, the as-prepared NiZnFe LDHs nanosheets were treated with $5 \mathrm{M}$
$\mathrm{NaOH} 60 \mathrm{~min}$ at room temperature. The obtained product was washed with ethanol and water three times, dried at $45^{\circ} \mathrm{C}$ for 8 h. The $\mathrm{Ni}_{x} \mathrm{Fe} \mathrm{LDH}$ s nanosheets were synthesized.

\section{Synthesis of $\mathrm{Pt}_{3} \mathrm{Ni}_{1} / \mathrm{Ni}_{x} \mathrm{Fe}$ LDHs, $\mathrm{Pt}_{1} \mathrm{Ni}_{1} / \mathrm{Ni}_{x} \mathrm{Fe} \mathrm{LDHs}, \mathrm{Pt}_{1} \mathrm{Ni}_{3} / \mathrm{Ni}_{x} \mathrm{Fe}$ LDHs, and $\mathrm{Pt} / \mathrm{Ni}_{\mathrm{x}} \mathrm{Fe}$ LDHs nanosheets}

The electrochemical deposition of PtNi and Pt on $\mathrm{Ni}_{x} \mathrm{Fe}$ LDHs nanosheets surface was similar to the NiFe LDHs synthesis process. Particularly, the as-obtained $\mathrm{Ni}_{x} \mathrm{Fe} \mathrm{LDHs}$ on NF was directly used as the working electrode, Pt plate and $\mathrm{Ag} / \mathrm{AgCl}(3$ $\mathrm{M} \mathrm{KCl}$ ) as the counter electrode and reference electrode, respectively. The electrochemical deposition of $\mathrm{PtNi} / \mathrm{Ni}_{x} \mathrm{Fe} \mathrm{LDHs}$ was performed in a $0.2 \mathrm{M} \mathrm{Na}_{2} \mathrm{SO}_{4}$ aqueous solution containing $\mathrm{H}_{2} \mathrm{PtCl}_{6} \cdot 6 \mathrm{H}_{2} \mathrm{O}$ and $\mathrm{NiSO}_{4} \cdot 6 \mathrm{H}_{2} \mathrm{O}$, while the total moles of $\mathrm{PtCl}_{6}{ }^{2-}$ and $\mathrm{Ni}^{2+}$ in the electrolyte was kept at $0.004 \mathrm{M}$. The potentiostatic deposition was carried out at $-1.0 \mathrm{~V}(\mathrm{vs} . \mathrm{Ag} / \mathrm{AgCl})$ for $300 \mathrm{~s}$ at $4{ }^{\circ} \mathrm{C}$. By varying the molar ratio of platinum salt and nickel salt precursor used, $\mathrm{PtNi} / \mathrm{Ni}_{\mathrm{x}} \mathrm{Fe}$ LDHs with different alloy proportions could be tuned. The product prepared from molar ratio $\mathrm{Pt}: \mathrm{Ni}=4: 0,3: 1,1: 1$ and $1: 3$ were denoted as $\mathrm{Pt} / \mathrm{Ni}_{\mathrm{x}} \mathrm{Fe}$ LDHs, $\mathrm{Pt}_{3} \mathrm{Ni}_{1} / \mathrm{Ni}_{\mathrm{x}} \mathrm{Fe}$ LDHs, $\mathrm{Pt}_{1} \mathrm{Ni}_{1} / \mathrm{Ni}_{\mathrm{x}} \mathrm{Fe}$ LDHs, and $\mathrm{Pt}_{1} \mathrm{Ni}_{3} / \mathrm{Ni}_{\mathrm{x}} \mathrm{Fe}$ LDHs, respectively.

\section{Electrochemical measurements}

All electrochemical measurements were performed with a three-electrode system using a CH760E electrochemical workstation at room temperature. To show the practical application potential, the synthesized electrocatalysts coated on NF $\left(1^{*} 1 \mathrm{~cm}^{2}\right)$ were directly used as the working electrode. A Pt plate and an $\mathrm{Ag} / \mathrm{AgCl}(3 \mathrm{M} \mathrm{KCl})$ electrode were used as the counter electrode and reference electrode, respectively. All potentials measured were calibrated to the reversible hydrogen electrode (RHE) according to the Nernst equation: $\mathrm{E}_{\mathrm{RHE}}=\mathrm{E}_{\mathrm{Ag} / \mathrm{AgCl}}+0.059 * \mathrm{pH}+0.197 \mathrm{~V}$. The linear sweep voltammograms (LSVs) were collected at the scanning rate of 10 $\mathrm{mV} \mathrm{s}^{-1}$ without $i R$ compensation. All polarization curves were recorded after activating with constant current density chronopotentiometry scanning until reaching a stable state. The OER was investigated in $1 \mathrm{M} \mathrm{KOH}$ electrolyte, while the ORR experiment was conducted in an $\mathrm{O}_{2}$-saturated $0.1 \mathrm{M} \mathrm{KOH}$ aqueous solution.

The ECSA values for OER as-made samples were measured at the non-Faradaic region range (1.173-1.273 V, vs. RHE, $1 \mathrm{M}$ $\mathrm{KOH})$ with scan rates of $10,25,50,100$ and $200 \mathrm{mV} \mathrm{s}^{-1}$, respectively. The double-layer capacitance $\left(C_{d 1}\right)$ is estimated by plotting the $\Delta j\left(j_{a}-j_{c}\right)$ at $1.223 \mathrm{~V}$ against the scan rate, where $j_{a}$ and $j_{\mathrm{c}}$ are anodic and cathodic current density respectively, and the linear slope is equivalent to twice of the double-layer capacitance.

The electrochemically active surface area (ECSA) toward ORR was calculated by measuring the area of $\mathrm{H}$ desorption after the deduction of the double layer region via $\mathrm{CVs}_{\mathrm{s}}$ in $\mathrm{O}_{2}$-saturated $0.1 \mathrm{M} \mathrm{KOH}$ solutions at a scan rate of $20 \mathrm{mV} \mathrm{s}^{-1} .^{34}$ The ECSA of Pt can be calculated on the following equation:

$$
E C S A=\frac{Q_{H}}{m \times 0.21}
$$


where, $Q_{H}$ represents the charge of $\mathrm{H}$ desorption, $m$ is the loading amount of metal, 0.21 represents required for monolayer oxidize of $\mathrm{H}_{2}$ on Pt surface.

The catalyst ink was prepared by adding $5 \mathrm{mg}$ ground catalyst into $0.95 \mathrm{~mL}$ ethanol and $0.05 \mathrm{~mL}$ Nafion solution ( $5 \mathrm{wt} \%$, SigmaAldrich) mixed solvent, and sonicated for at least $30 \mathrm{~min}$. The mass loading of $20 \% \mathrm{Pt} / \mathrm{C}$ (Macklin) and $20 \% \mathrm{Ir} / \mathrm{C}$ (Premetek) on to NF substrates is $0.1 \mathrm{mg} \mathrm{cm}^{-2}$.

\section{Assembly and test of the hybrid sodium air batteries (HSABs)}

The hybrid Na-air battery was assembled in a sandwich structure. Initially, the anode part of the hybrid Na-air cell was fabricated in a glove box. The metallic sodium was cut and pressed into a sheet with a diameter of $10 \mathrm{~mm}$ as the anode, followed by injection of organic electrolyte $\left(1 \mathrm{M} \mathrm{NaClO}{ }_{4}\right.$ in tetraethylene glycol dimethyl ether) to the anode chamber. Then, the solid electrolyte NASICON was sealed as the separator to the anode and cathode chamber, ensuring that one side of the NASICON was in contact with the organic electrolyte and the other side was exposed to air. NASICON solid electrolyte was chosen to avoid direct contact between aqueous electrolyte and $\mathrm{Na}$ anode, and specifically allow $\mathrm{Na}$ ions shuttle between anode and cathode during reactions. The cathode compartment was built under the ambient air by directly immersing the air electrode in the $\mathrm{O}_{2}$-saturated $0.1 \mathrm{M} \mathrm{NaOH}$ electrolyte. The asmade electrocatalysts coated on NF (diameter $10 \mathrm{~mm}$ ) were directly used as air cathodes. For comparison, the $20 \% \mathrm{Pt} / \mathrm{C}$ (Macklin) and 20\% Ir/C (Premetek) catalysts cast onto NF (diameter $10 \mathrm{~mm}$ ) were prepared with a mass loading of $1 \mathrm{mg}$ $\mathrm{cm}^{-2}$.

All tests for the HSABs were performed on a battery test station (CT2001 A, Wuhan LAND electronics). Cycling performance was tested by recurrent galvanostatic pulses for $10 \mathrm{~min}$ of discharge followed by $10 \mathrm{~min}$ of charge at room temperature.

\section{Physical Characterization}

The microstructures of all samples were investigated by scanning electron microscopy (SEM, Zeiss Sigma) and transmission electron microscopy (TEM, Talos F200S, 200kV). The Fourier transform infrared spectroscopy (FTIR) was conducted with on Nicolet 6700 spectrometer (Thermo, America). The crystal structures of the obtained samples were analyzed using a powder X-ray diffractometer (XRD, Rigaku Smartlab, CuKa1). The X-ray photoelectron spectroscopy (XPS) was carried out on Thermo Scientific ESCALAB $\mathrm{Xi}^{+}$XPS Microprobe. The Raman spectroscopy was performed on Horiba LABHRev-UV.

\section{Theoretical Calculations Section}

All the calculations were based on density functional theory (DFT) to optimize geometry structures, which is performed using the Vienna ab-initio Simulation Package (VASP). ${ }^{35,}{ }^{36}$ The exchange-correlation interactions of the generalised gradient approximation (GGA) in the scheme proposed by PerdewBurke-Ernzerhof functional (PBE). ${ }^{37}, 38$ The effect of core electrons on the valence electron density was described by The
Projector Augmented Wave (PAW) method. ${ }^{39}$ The cut-off kinetic energies for the plane waves are set to $450 \mathrm{eV}$ for all the calculations. In this context, we used a $3 \times 3$ supercell (a total of 182 atoms) with a three nickel atoms vacancy from NiFe LDHs monolayer, to reach an atoms stoichiometries $x$, as shown in Fig. 5. We set the Brillouin zone with a Gamma-centered k-point grid of $1 \times 1 \times 1$ due to a large number of atoms. ${ }^{40}$ The convergence tolerance of energy and force on each atom during structure relaxation is less than $10^{-4} \mathrm{eV}$ and $0.02 \mathrm{eV} / \mathrm{A}^{\circ}$, and a vacuum space of around $20 \AA$ was set along the $z$ direction to avoid the interaction between periodical images. Also, Grimme's DFT-D3 scheme was used through the employ of the dispersion correction to describe van der Waals (vdW) interactions in the systems. ${ }^{41,}{ }^{42}$ Hubbard-U Correction method was applied to improve the description of localized $\mathrm{Ni}$ and $\mathrm{Fe}$ delectrons in the NiFe LDHs with $U=5.3$ and $U=6.45$ for Fe and $\mathrm{Ni}$, respectively. Spin polarization was also considered in all the calculations.

The Gibbs reaction free energy change $(\Delta \mathrm{G})$ of each elementary step in ORR/OER was evaluated based on the computational hydrogen electrode (CHE) model developed by Nørskov and coworkers. ${ }^{27}$ At alkaline environment, the ORR proceeds (1) in four electrons steps and can be written as follows:

$$
\begin{gathered}
\mathrm{O}_{2}(g)+\mathrm{H}_{2} \mathrm{O}(\mathrm{I})+e^{-}+{ }^{*} \rightarrow{ }^{*} \mathrm{OOH}+\mathrm{OH}- \\
{ }^{*} \mathrm{OOH}+e^{-} \rightarrow{ }^{*} \mathrm{O}+\mathrm{OH}^{-} \\
{ }^{*} \mathrm{O}+\mathrm{H}_{2} \mathrm{O}(\mathrm{I})+e^{-} \rightarrow{ }^{*} \mathrm{OH}+\mathrm{OH}^{-} \\
{ }^{*} \mathrm{OH}+e^{-} \rightarrow \mathrm{OH}^{-}+{ }^{*}
\end{gathered}
$$

where $*$ presents an adsorption site on the catalyst, and ${ }^{*} \mathrm{OH}$, ${ }^{*} \mathrm{O}$, and ${ }^{*} \mathrm{OOH}$ denotes the corresponding absorbed intermediates. The four-electron reaction mechanism of OER is the reverse of ORR. Then, at standard conditions, the free energy $(\triangle G)$ is further calculated by the formula:

$$
\Delta G=\Delta E+\Delta Z P E-T \Delta S-q U+k_{B} T \ln 10^{*}(p H)
$$

Therefore, the theoretical overpotential $\eta$ for ORR is defined in equation (3):

$$
\eta_{\text {Theory }}=1.23 \mathrm{~V}-\max (\Delta G 1, \Delta G 2, \Delta G 3, \Delta G 4) / e^{-}
$$

the theoretical overpotential $\eta$ for OER is defined in equation (4):

$$
\eta_{\text {Theory }}=\max (\Delta G 1, \Delta G 2, \Delta G 3, \Delta G 4) / e-1.23 \mathrm{~V}
$$

Moreover, the above-mentioned binding energy $\left(\Delta \mathrm{E}_{\mathrm{ads}}\right)$ for $* \mathrm{OOH},{ }^{*} \mathrm{O}$, and ${ }^{*} \mathrm{OH}$ could be calculated by the following equation:

$$
\begin{gathered}
\Delta E{ }_{* \mathrm{OOH}}=E_{*{ }^{* O O H}}{ }^{*} E-\left(2 E_{\mathrm{H} 2 \mathrm{O}}-3 / 2 E_{\mathrm{H} 2}\right) \\
\Delta E^{* O}=E^{*}{ }^{-}{ }^{*} E-\left(E_{\mathrm{H} 2 \mathrm{O}}-E_{\mathrm{H} 2}\right) \\
\Delta E{ }^{*} \mathrm{OH}=E{ }^{* \mathrm{OH}^{-}}{ }^{*} E-\left(E_{\mathrm{H} 2 \mathrm{O}}-1 / 2 E_{\mathrm{H} 2}\right)
\end{gathered}
$$

where $\mathrm{E}_{* \mathrm{OOH}}, \mathrm{E}_{*} \mathrm{O}, \mathrm{E}_{*} \mathrm{OH}$ and ${ }^{*} \mathrm{E}$ represent the calculated DFT total energy of the pristine substrate and those absorbed with $* \mathrm{OOH}$, ${ }^{*} \mathrm{O}$, and ${ }^{*} \mathrm{OH}$, respectively, and $\mathrm{E}_{\mathrm{H} 2 \mathrm{O}}$ and $\mathrm{E}_{\mathrm{H} 2}$ are the total energy of $\mathrm{H}_{2} \mathrm{O}$ and $\mathrm{H}_{2}$ molecules in the gas phase, respectively.

\section{Conflicts of interest}

There are no conflicts to declare.

\section{Acknowledgements}


This work was supported by the Science and Technology Development Fund of the Macau SAR (FDCT 0062/2018/A2, FDCT191/2017/A3, FDCT0041/2019/A1, and FDCT0046/2019/AFJ) and Multi-Year Research Grants (MYRG2019-00055-IAPME, MYRG2017-00216-FST, and MYRG2018-00192-IAPME) from the University of Macau, and the UEA funding.

\section{References}

1

H. Yadegari and X. Sun, Acc. Chem. Res., 2018, 51, 15321540.

2

Y. Kim, G.-T. Kim, S. Jeong, X. Dou, C. Geng, Y. Kim and S. Passerini, Energy Storage Mater., 2019, 16, 56-64.

X. Xu, K. San Hui, D. A. Dinh, K. N. Hui and H. Wang, Mater. Horiz., 2019, 6, 1306-1335.

Q. Sun, J. Liu, B. Xiao, B. Wang, M. Banis, H. Yadegari, K. R. Adair, R. Li and X. Sun, Adv. Funct. Mater., 2019, 29, 1808332.

J. Han, X. Meng, L. Lu, Z. L. Wang and C. Sun, Nano Energy, 2020, 104669.

Q. Xie, Z. Cai, P. Li, D. Zhou, Y. Bi, X. Xiong, E. Hu, Y. Li, Y. Kuang and X. Sun, Nano Res., 2018, 11, 4524-4534.

Z. Lu, W. Xu, W. Zhu, Q. Yang, X. Lei, J. Liu, Y. Li, X. Sun and X. Duan, Chem. Commun., 2014, 50, 6479-6482.

P. Li, X. Duan, Y. Kuang, Y. Li, G. Zhang, W. Liu and X. Sun, Adv. Energy Mater., 2018, 8, 1703341.

M. Gong, Y. Li, H. Wang, Y. Liang, J. Z. Wu, J. Zhou, J. Wang, T. Regier, F. Wei and H. Dai, J Am. Chem. Soc., 2013, 135, 8452-8455.

Y. Wang, M. Qiao, Y. Li and S. Wang, Small, 2018, 14, 1800136.

Z. Li, M. Shao, H. An, Z. Wang, S. Xu, M. Wei, D. G. Evans and X. Duan, Chem. Sci., 2015, 6, 6624-6631.

Q. Sun, Y. Dong, Z. Wang, S. Yin and C. Zhao, Small, 2018, 14, 1704137.

3 L. Yu, J. F. Yang, B. Y. Guan, Y. Lu and X. W. Lou, Angew. Chem. Int. Ed., 2018, 57, 172-176.

X. Lu and C. Zhao, Nat. Commun., 2015, 6, 1-7.

J. Zhang, X. Wu, W.-C. Cheong, W. Chen, R. Lin, J. Li, L. Zheng, W. Yan, L. Gu and C. Chen, Nat. Commun., 2018, 9, 1-8.

X. Tian, X. Zhao, Y.-Q. Su, L. Wang, H. Wang, D. Dang, B. Chi, H. Liu, E. J. Hensen and X. W. D. Lou, Science, 2019, 366, 850-856.

1 S. Anantharaj, K. Karthick, M. Venkatesh, T. V. Simha, A. S. Salunke, L. Ma, H. Liang and S. Kundu, Nano Energy, 2017, 39, 30-43.

G.-R. Zhang and S. Wöllner, Appl. Catal. B-Environ., 2018, 222, 26-34.

C. Li, H. Tan, J. Lin, X. Luo, S. Wang, J. You, Y.-M. Kang, Y. Bando, Y. Yamauchi and J. Kim, Nano Today, 2018, 21, 91105.

B. Han, C. E. Carlton, A. Kongkanand, R. S. Kukreja, B. R. Theobald, L. Gan, R. O'Malley, P. Strasser, F. T. Wagner and Y. Shao-Horn, Energy Environ. Sci., 2015, 8, 258-266.

C. Wei, R. R. Rao, J. Peng, B. Huang, I. E. L. Stephens, M. Risch, Z. J. Xu and Y. Shao-Horn, Adv. Mater., 2019, 31, 1806296.

D. Fang, X. Tang, L. Yang, D. Xu, H. Zhang, S. Sun, Z. Shao and B. Yi, Nanoscale, 2019, 11, 9091-9102.
L. Han, S. Dong and E. Wang, Adv. Mater., 2016, 28, 92669291.

C. Chen, Y. Kang, Z. Huo, Z. Zhu, W. Huang, H. L. Xin, J. D. Snyder, D. Li, J. A. Herron and M. Mavrikakis, Science, 2014, 343, 1339-1343.

M. Favaro, C. Valero-Vidal, J. Eichhorn, F. Toma, P. Ross, J. Yano, Z. Liu and E. Crumlin, J. Mater. Chem. A, 2017, 5, 11634-11643.

C. Cui, L. Gan, M. Heggen, S. Rudi and P. Strasser, Nat. Mater., 2013, 12, 765-771.

J. K. Nørskov, J. Rossmeisl, A. Logadottir, L. Lindqvist, J. R. Kitchin, T. Bligaard and H. Jonsson, J. Phys. Chem. B, 2004, 108, 17886-17892.

G. Chen, K. A. Kuttiyiel, M. Li, D. Su, L. Du, C. Du, Y. Gao, W. Fei, G. Yin and K. Sasaki, J. Mater. Chem. A, 2018, 6, 2072520736.

Z. W. Gao, J. Y. Liu, X. M. Chen, X. L. Zheng, J. Mao, H. Liu, T. Ma, L. Li, W. C. Wang and X. W. Du, Adv. Mater., 2019, 31, 1804769.

J. Gu, S. Magagula, J. Zhao and Z. Chen, Small Methods, 2019, 3, 1800550.

Y. Wu, X. Qiu, F. Liang, Q. Zhang, A. Koo, Y. Dai, Y. Lei and X. Sun, Appl. Catal. B-Environ., 2019, 241, 407-414.

J. K. Kim, E. Lee, H. Kim, C. Johnson, J. Cho and Y. Kim, ChemElectroChem, 2015, 2, 328-332.

P. Manikandan, K. Kishor, J. Han and Y. Kim, J. Mater. Chem. A, 2018, 6, 11012-11021.

M. Luo, Z. Zhao, Y. Zhang, Y. Sun, Y. Xing, F. Lv, Y. Yang, X. Zhang, S. Hwang, Y. Qin, J. Ma, F. Lin, D.Su, G. Lu and S. Guo, Nature, 2019, 574, 81-85.

S. Grimme, J. Comput. Chem., 2006, 27, 1787-1799.

G. Kresse and J. Furthmüller, Phys. Rev. B, 1996, 54, 11169. J. P. Perdew, K. Burke and M. Ernzerhof, Phys. Rev. lett., 1996, 77, 3865.

J. P. Perdew and Y. Wang, Phys. Rev. B, 1992, 46, 12947.

P. E. Blöchl, Phys. Rev. B, 1994, 50, 17953.

D. Chadi, Phys. Rev. B, 1977, 16, 1746.

S. Grimme, J. Antony, S. Ehrlich and H. Krieg, J. Chem. Phys., 2010, 132, 154104.

S. Grimme, S. Ehrlich and L. Goerigk, J. Comput. Chem., 2011, 32, 1456-1465. 